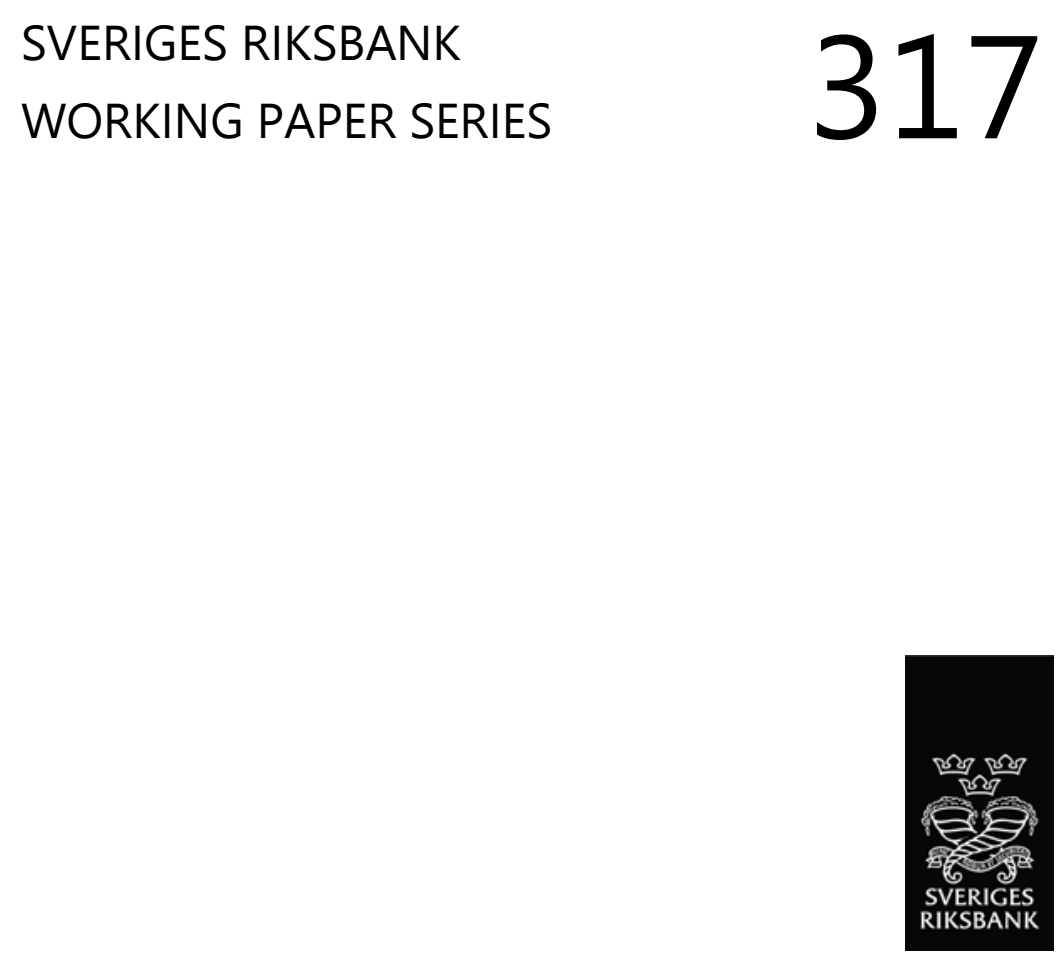

Subprime Borrowers, Securitization and the Transmission of Business Cycles

Anna Grodecka

March 2016 


\section{WORKING PAPERS ARE OBTAINABLE FROM}

www.riksbank.se/en/research

Sveriges Riksbank $\cdot$ SE-103 37 Stockholm

Fax international: +468210531

Telephone international: +4687870000

The Working Paper series presents reports on matters in the sphere of activities of the Riksbank that are considered to be of interest to a wider public.

The papers are to be regarded as reports on ongoing studies and the authors will be pleased to receive comments.

The opinions expressed in this article are the sole responsibility of the author(s) and should not be interpreted as reflecting the views of Sveriges Riksbank. 


\title{
Subprime Borrowers, Securitization and the Transmission of Business Cycles*
}

\author{
Anna Grodecka ${ }^{\dagger}$
}

\author{
Sveriges Riksbank Working Paper Series
}

No. 317

March 2016

\begin{abstract}
A growing literature (i.e. Jaffee, Lynch, Richardson, and Van Nieuwerburgh, 2009, Acharya and Schnabl, 2009) argues that securitization improves financial stability if the securitized assets are held by capital market participants, rather than financial intermediaries. I construct a quantitative macroeconomic model with a novel specification for mortgage-backed securities (MBS) to evaluate this claim for subprime securitization during the Great Recession. I find that output in the U.S. would have dropped by only about a third and house prices by only a half of what we actually observed, if subprime MBS had been purchased by non-financial agents, rather than held by banks. This is because banks are subject to capital requirements and if MBS remain within the banking system, the fall in their value puts a strain on banks' balance sheets. The subsequent deleveraging amplifies business cycles. My findings suggest that the existence of the securitization market stabilizes the economy under the condition that financial intermediaries do not engage in the acquisition of securitized assets.
\end{abstract}

\section{Keywords: Subprime Borrowers, Securitization, Financial Intermediation, Great Recession}

JEL Classification: E32, E44, G01, G13, G21, R21

\footnotetext{
* I would like to thank Jürgen von Hagen and Gernot Müller for their insightful comments. I also thank Nuno Coimbra, Christopher M. Gunn, Michael Evers, Isaiah Hull, Ethan Ilzetzki, Philip Jung, Florian Kirsch, Alexander Kriwoluzky, Johannes Pfeifer, Raùl Razo-Garcia and Kevin Sheedy, as well as seminar participants at the Macro and Finance Workshop at Bonn University, the Macro PHD work-in-progress workshop at the LSE, the EDP Jamboree 2012 in Florence, EEA-ESEM 2014 in Toulouse, the EDP Jamboree 2014 in Paris, the VfSJahrestagung 2014 in Hamburg, the 46. Konstanz Seminar on Monetary Theory and Policy. Financial support by the Deutsche Forschungsgemeinschaft (DFG) through the Bonn Graduate School of Economics (BGSE) is gratefully acknowledged. The views expressed in this paper are solely the responsibility of the author and should not be interpreted as reflecting the views of Sveriges Riksbank.

$\dagger$ Sveriges Riksbank, e-mail: anna.grodecka@riksbank.se.
} 


\section{Introduction}

A common point of departure for researchers analyzing the Great Recession is often the relatively small subprime mortgage market in the U.S. that may have been one of the roots of the prolonged downturn, and the securitization of subprime loans. Departing from there, this paper investigates potential sources of the amplification mechanism during the recent crisis in the U.S. market. It provides a numerical interpretation to the claim by Jaffee, Lynch, Richardson, and Van Nieuwerburgh (2009) (p.71) who conclude: "The financial crisis occurred because financial institutions did not follow the business model of securitization. Rather than acting as intermediaries by transferring the risk from mortgage lenders to capital market investors, they became the investors. They put 'skin in the game"'. A counterfactual exercise, presented in the paper, shows that if only financial institutions had followed 'the business model of securitization', the U.S. output fall in the Great Recession would account only to about one third of the observed. These results hold even if we assume that the subprime defaults are at the pre-crisis level. This is because non-financial agents can cushion subprime defaults better than capitalconstrained financial intermediaries. Banks that hold MBS tranches whose value is falling in a downturn deleverage to meet their capital requirements. As a consequence, the reduced lending to households and corporations puts a strain on economy's output. As such, my findings suggest that the existence of the securitization market dampens business cycles under the condition that financial intermediaries do not engage in the acquisition of securitized assets.

This paper presents a calibrated model in a linear New-Keynesian Dynamic Stochastic General Equilibrium (DSGE) framework that builds on models with credit frictions, particularly collateral constraints (á la Iacoviello, 2005). The focus is on the role of subprime mortgages and securitization in the recent crisis, and the importance of the bank lending channel in the presence of binding capital requirements. The model incorporates some aspects of financial modeling (mortgage-backed securities, MBS) into a standard macroeconomic framework, which is the main contribution of this paper. Three different versions of the model are compared: a benchmark model without securitization, a model with securitization in which only nonfinancial agents buy securitized assets, and a model with securitization in which also financial intermediaries acquire asset backed securities. The latter model can be seen as the most realistic description of the crisis, while the former two are counterfactuals. I leave aside the modeling of the portfolio decisions of agents. The aim of the exercise is much more modest; assuming that securitization took place and securitized products were bought by different agents in the economy, I want to investigate whether there is any difference in the reaction of the economy to different shocks, depending on who is the ultimate bearer of the subprime risk.

It turns out that the securitization of subprime mortgages may have caused an amplification of the crisis through the balance sheet effects of banks that were holding the securitized 
products. If MBS were held by non-banks, securitization would have had a positive effect of risk-spreading, leading to a smoother response of output to different shocks. Securitization itself thus cannot be blamed for the severity of the crisis. The results of this paper support the proposition that in principle, securitization, even of the 'dangerous' subprime risk, makes sense, because different market participants have different investment horizons and may be better able to bear the credit risk than the originator. Ideally, securitized products would end up in the portfolios of institutions such as pension funds that can cushion short-term losses better than financial intermediaries. The problem occurs if banks themselves engage in such transactions, because they mainly rely on short-term funding and play the role of financial intermediary in the economy. IMF (2009) reports that, at the end of 2006, banks accounted for ca. $51 \%$ of total financial institutions' (banks, hedge funds, insurance companies, finance companies, mutual funds, pension funds) exposure to the subprime market, either directly or indirectly (see Acharya, Schnabl, and Suarez, 2013). ${ }^{1}$ The present model shows that, if banks facing capital requirements buy MBS tranches, which lose value in the downturn, the capital requirement gets tighter, so the whole intermediation process is disrupted. Through the deleveraging process, lending to other agents in the economy declines, causing a credit crunch, partial termination of production and a fall in output. The model demonstrates the relevance of this process in a general equilibrium framework and offers a theoretical explanation for the negative correlation between subprime defaults and commercial lending observed for U.S. banks during the crisis. It is important to note that, although this paper is motivated by the events in the subprime securitization market and hence, I model specifically the securitization of adjustablerate mortgages, the main mechanism through which securitization impacts the economy in the model is the balance sheet dynamics of financial intermediaries. Therefore, the model is also applicable to the securitization of different types of assets, not only mortgages.

The present paper relates to three main strands of the literature. It is an extension of Iacoviello (2005) that relies on the seminal paper by Kiyotaki and Moore (1997). In both models, the importance of collateral constraints and the imperfect enforcement of lenders' rights that lead to the establishment of a certain loan to value ratio are emphasized. Iacoviello (2005) focuses on loans backed by real estate, which makes his model a natural starting point for my exercise investigating the role of subprime securitization. I extend the model by adding the two-sector banking industry and considering the securitization of subprime loans. The balance sheet effects discussed in the paper resemble dynamics occurring in Iacoviello (2014) that models the consequences of an exogenous fall in banks' equity. The second strand of literature important for this paper is mainly represented by Adrian and Shin (2010) and Adrian and Shin (2011) that focus on the balance sheets of financial intermediaries and the empirical proper-

\footnotetext{
${ }^{1}$ Due to the Rule 114A, adopted in 1990, allowing unregistered release of certain securities to so-called qualified institutional buyers, it is very difficult to assess the financial sectors' exposure to the subprime risk.
} 
ties of the behavior of banks. Lastly, the empirical evidence on the recent crisis delivers many insights. The present paper mainly relies on a comprehensive study of Gorton (2008), who describes in detail the subprime mortgage market in the U.S. and the securitization of subprime mortgages. Another important reference is Gorton and Souleles (2007) who describe the basics of the securitization process. Hellwig (2009) also delivers an extensive descriptive analysis of the events leading to the Great Recession.

When it comes to the modeling of securitization in a general equilibrium macroeconomic model, to my knowledge only three attempts have been made, and all of them focus on the problem of asymmetric information. Faia (2011) models the secondary market for bank loans in a model in which several economic agents face a moral hazard problem. On the one hand, capital producers that obtain funds from banks may choose to exert low effort, which undermines the success probability of their project, but provides them with a private benefit. On the other hand, the incentive to monitor the projects decreases for bankers, once a secondary market for loans exists. Faia (2011) concludes that the existence of secondary markets amplifies the dynamics of macro variables. Hobijn and Ravenna (2010) model securitization in a setup with banks that have access to costly screening which provides them with information about the credit score of borrowers. Borrowing households are either honest or dishonest, which leads to default events. Hobijn and Ravenna (2010) demonstrate that securitization reduces the equilibrium interest rates, and the decline is most pronounced for riskier, subprime borrowers who gain the most from the securitization process. The authors examine the response of financial variables, such as interest rate spreads, to a monetary and financial shock and conclude that with securitization the reaction of financial variables is amplified in comparison to a standard NewKeynesian model. Lastly, Kuncl (2014) analyzes the role of asymmetric information in the secondary loan market, in a setup in which firms with profitable investment opportunities sell the cash-flows from their projects to firms with low or no investment opportunities. Although all three papers deal with securitization, the focus and modeling devices applied in these papers differ considerably from the setup in this paper. Firstly, I focus on the real estate market, which is not described in any of the discussed papers. Secondly, in this paper, the intermediation role of banks (absent in Kuncl, 2014) plays an important part, as well as the interbank market. Finally, while information asymmetry is at the heart of analysis of the other three papers, in this work it appears only indirectly through the existence of borrowing and capital constraints.

Why is it important to consider recent developments in a general equilibrium macro framework when the finance and microeconomics literature deliver a fairly good description of economic agents' incentives and amplification processes caused by financial frictions? The general equilibrium macroeconomic setup is especially useful for examining the positive aspects of securitization through inter-market linkages and quantifying them. To show why securitization may smooth out the business cycle, I explicitly model the interbank sector. When distinct finan- 
cial intermediaries are connected through loan and deposit contracts (i.e. assets of one banking institution correspond to liabilities of another banking institution), changes in the balance sheet of one of them will automatically lead to changes in the balance sheet of the second intermediary. Securitization of subprime loans releases the pressure on the subprime loan originators' balance sheets, which, through the interbank market, has a positive effect on the balance sheets of other financial intermediaries in the economy, since they finance subprime lenders with deposits. This positive aspect of securitization is present in all versions of the model with securitization that I consider. However, the overall impact of securitization on the economy depends on other endogenously arising processes. It turns out that the effect on business cycle fluctuations may be amplifying, if the deleveraging effect, present in the model with banks investing in MBS, is stronger than the positive effect of securitization. Moreover, deleveraging may lead to a vicious circle of falls in asset prices and further deleveraging (Adrian and Shin, 2010), leading even to instability of the system, if capital requirements imposed on banks are very low. Low capital requirements lead to higher leverage and subsequently, more pronounced deleveraging, when a negative shock hits the economy.

The model presented in this paper is complex, as it incorporates agents differing in their impatience level, two types of bankers, as well as diverse collateral constraints. Yet, the main mechanism presented in the paper is simple - binding collateral constraints faced by financial intermediaries may lead to disruptions in the lending market and may amplify losses from an exogenous negative shock, leading to a decline in output. I show that to understand the impact of securitization on the financial intermediation market, one has to take into account the heterogeneity among banks and their effectively different capital requirements resulting from different portfolios. The analysis of the banking and the interbank market is very important, as it matters not only whether the securitized products are being held by the banking or the nonbanking sector, but also which bank holds which kind of products. In what follows, I describe the peculiarities of the subprime market (Section 2.1) and some empirical relations between the MBS and commercial loans observed in the data during the crisis (Section 2.2), which will make the interpretation of chosen assumptions and modeling devices easier. Section 3 presents the baseline model and Section 4 is its extension with securitization. The main results are presented in Section 5, and Section 5.3 presents the results of the experiment, which provides the counterfactual for the crisis. Section 6 presents sensitivity analysis. The main conclusions of the paper are summarized in Section 7. 


\section{Stylized Facts}

\subsection{Subprime Mortgage Market}

It is remarkable that the events in the subprime mortgage market are important for the understanding of the roots of the crisis, because subprime borrowing accounts for only a small percentage of the whole mortgage market (the share of subprime originations is depicted in Figure 1). Although there is no exact definition of a subprime borrower or market, there are certain features common to all subprime loan contracts. Compared to prime borrowers, subprime borrowers have lower creditworthiness, as they sometimes even lack income or collateral (so called "NINJAs" - No Income, No Job or Assets, see Jovanovic̀, 2013). Their LTV ratios are higher than in the case of prime borrowers. ${ }^{2}$

Since subprime borrowers often do not have well-documented assets or income, it poses a challenge to create a loan contract that will enable them to pay the installments. The solutions to this problem were hybrid adjustable rate mortgages of type $2 / 28$ or $3 / 27$, in which the first period's ( 2 or 3 years) interest rate was fixed and the rest ( 28 or 27 years respectively) was varying. The shift from the fixed interest rate to the adjustable one occurred at a previously specified reset date. As Kliff and Mills (2007) note, before the outbreak of the crisis, these hybrid mortgages made up about two thirds of all ARM (adjustable rate mortgage) originations and were basically short-term fixed rate mortgages that converted into an adjustable rate mortgage after the initial period. Gorton (2008) explains how this kind of contract can be interpreted as a short-term contract, whose conditions depended on the changes in housing prices. In line with that interpretation, Amromin and Paulson (2010) provide evidence of a high sensitivity of defaults to changes in home prices among subprime borrowers already in the years before the crisis, compared to a very low sensitivity among prime borrowers (for 2004: -0.183 for subprime borrowers and -0.00166 for prime borrowers). The short-term characteristics of subprime loans as well as their high sensitivity to housing prices observed in the data enable me to model the subprime loan contract as a one-period contract with the possibility of default linked to changes in house prices.

How do developments in the subprime mortgage market relate to the economic performance of the U.S.? Figure 1 presents subprime loans originations as a share of the total market, nonagency securitization activity (RMBS - residential mortgage backed securities - and securities based on home equity loans), as well as the real GDP growth rate. The peak of subprime originations coincided with the peak in non-agency securitization activities and both of them almost dried out in 2008 (further data for subprime originations not available). This reflects

\footnotetext{
${ }^{2}$ More details on comparison between prime and subprime borrowers and their default and foreclosure statistics, both for adjustable and fixed interest rate loans, are provided in Appendix A.
} 


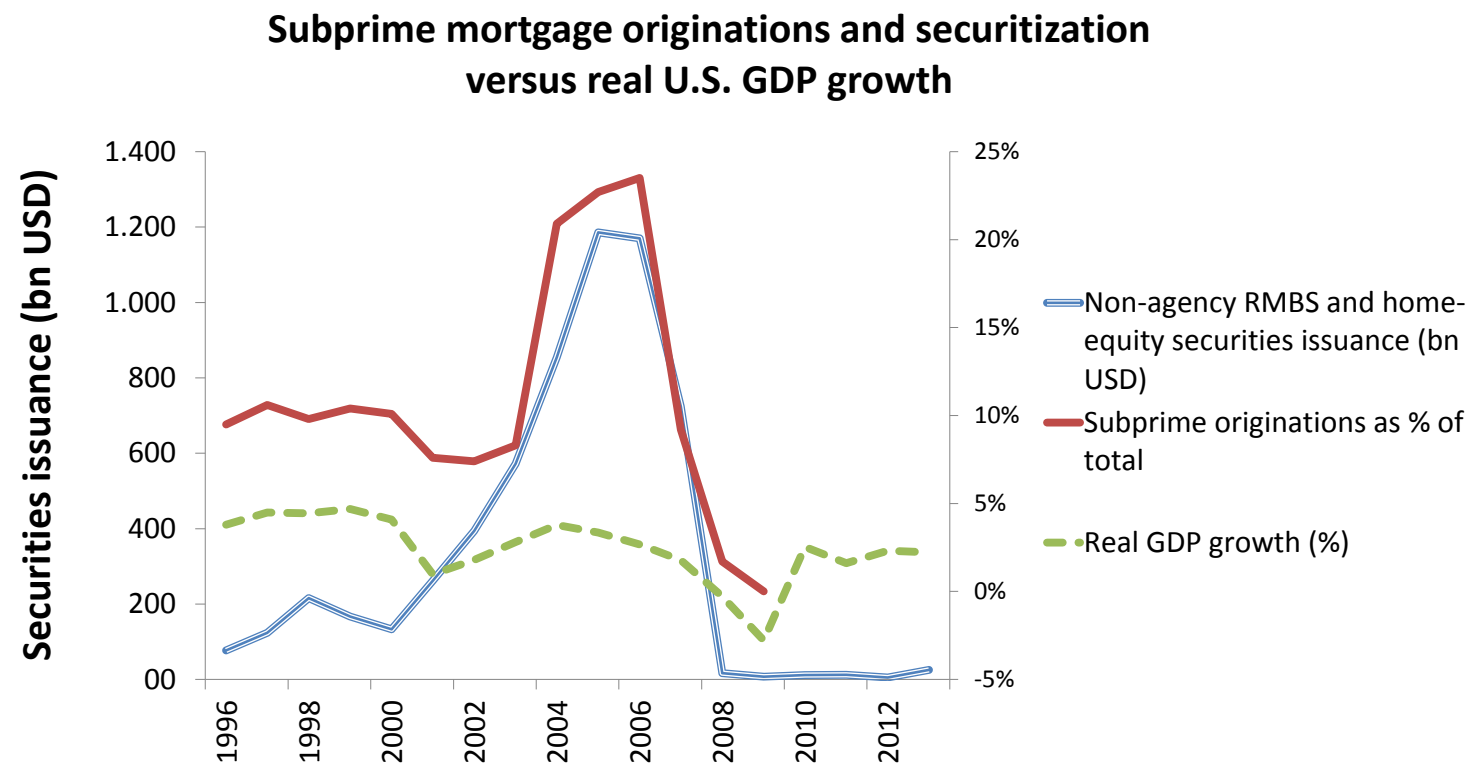

Source: SIMFA, NIPA table 1.1.1., Financial Crisis Inquiry Commission Report, p.70 Figure 5.2

Figure 1: Subprime market and real GDP (annual data)

the fact that securitization was the main financing method for subprime originations. ${ }^{3}$ The majority of subprime mortgages were pooled together and sold in the financial market as MBS, which were often a base for a further securitization instrument - a collateralized debt obligation (CDO). ${ }^{4}$ Subprime originations peaked in 2006, while the 4th quarter of 2006 denotes the peak in the U.S. house price index (USSTHPI). The developments in the housing and mortgage market led the changes in U.S. GDP growth.

\subsection{MBS and Commercial Loan Holdings by Banks}

As the banking sector and its holdings of MBS are crucial in this paper, I investigate the asset side of the balance sheets of U.S. banks. Figure 2 presents the fraction of MBS holdings, commercial real estate loans and commercial loans (all loans to firms, including real estate) in all bank assets over time. ${ }^{5}$ It is visible that the fractions of MBS and commercial real estate loans went into opposite directions from ca. 2007. ${ }^{6}$ The divergence in the fractions of MBS and commercial real estate loans is preceded by a large surge in subprime default rates that started

\footnotetext{
${ }^{3}$ A more detailed description of securitization process in provided in the Appendix B.

${ }^{4}$ The ratio of securitized subprime/Alt-A mortgages rose from 46\% in 2001 to $93 \%$ in 2007 (Geithner, 2011, p.11). Alt-A mortgages are mortgages with characteristics that places them between prime and subprime mortgages.

5 The graph is generated using data for large domestically-chartered commercial banks that are a good proxy for all U.S. banks and are chosen due to the better availability of data. A detailed data description is available in Appendix D.

${ }^{6}$ An analogous graph for lending levels that exhibits the same pattern can be found in Appendix C (Figure 16).
} 


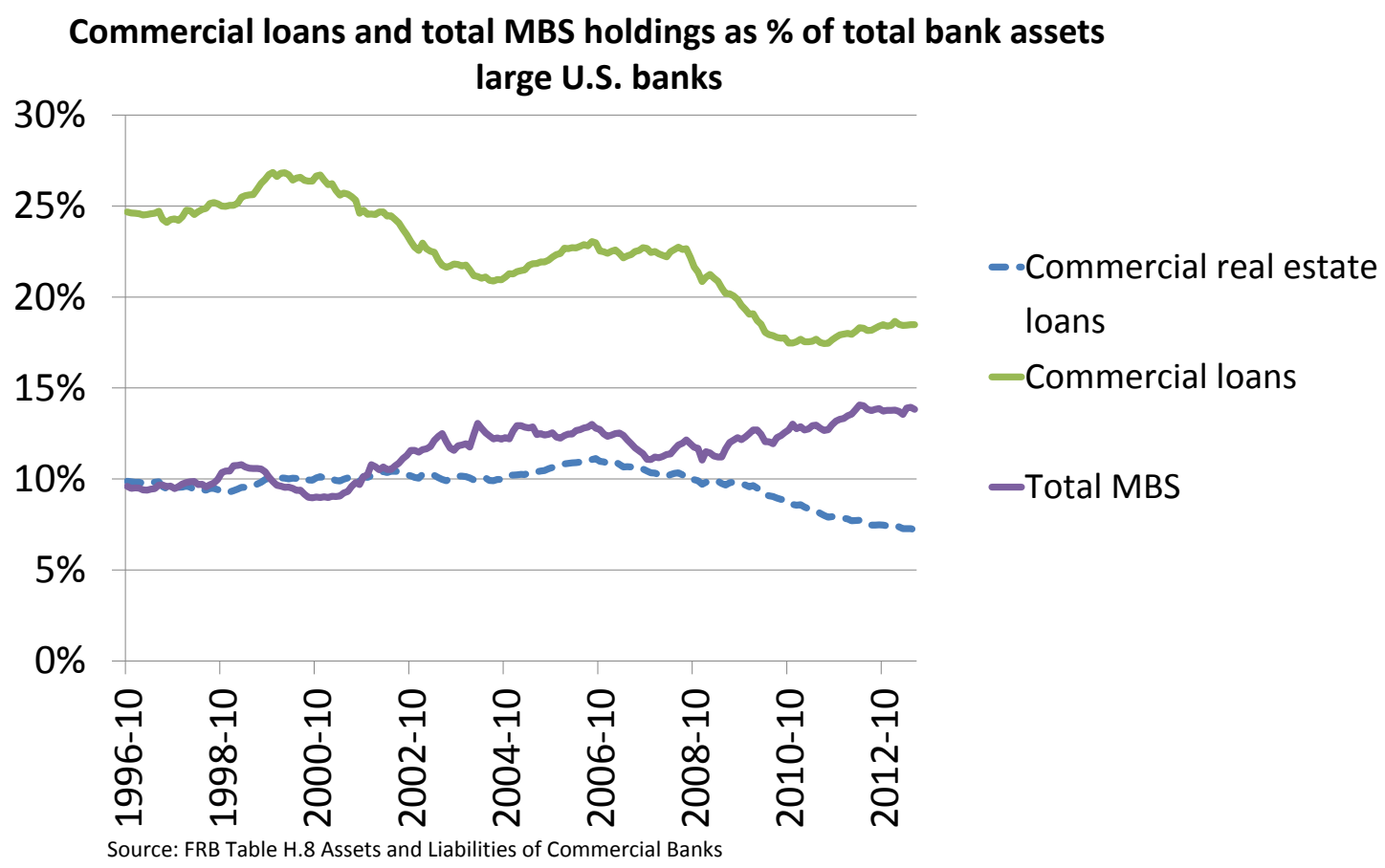

Figure 2: Composition of large banks' balance sheets

in 2006 and coincided with the beginning of the fall in housing prices (see Figure 15 in the Appendix C). The fraction of MBS and commercial real estate loans were approximately equal when expressed as a percentage of U.S. bank assets until the subprime default rates began to increase. Only with an increase in subprime delinquencies did the fraction of total MBS rise and the fraction of commercial real estate loans fall, suggesting that securitized assets experiencing a fall in value may have crowded out lending to entrepreneurs. The correlation between the fraction of commercial real estate loans on the asset side of the bank and the subprime default rates for the crisis period is clearly negative (see Figure 17 in Appendix C). The negative correlation does not imply any causal effects, but this paper offers an explanation for the empirical facts. Rising subprime default rates lead to a fall in the value of subprime loans or securitized products backed by these loans. This puts a strain on banks' balance sheets and forces them to deleverage, which reduces lending to firms. Why does the fraction of held MBS increase during the crisis despite the rising default rates on these securities? The banks, even if they wanted, could not sell the toxic assets as the market for them dried out when the scale of the crisis was made public: subprime MBS suddenly became illiquid. ${ }^{7}$

\footnotetext{
${ }^{7}$ The omnipresent illiquidity prompted the Federal Reserve to introduce some of its programs aimed at increasing liquidity, seehttp://www.marketwatch.com/story/ fed-starts-program-to-buy-illiquid-mortgage-assets, but the first acquisitions of toxic assets in 2009 were focused on guaranteed agency mortgages whose boom and bust was less pronounced than developments in the non-agency mortgage market. In fact, it turns out that the role of government is decisive for the shape of the graph shown in Figure 2. Figures 19 and 20 in the Appendix C provide more empirical evidence on that.
} 


\section{The Benchmark Model}

The model economy is inhabited by households that differ in their degree of impatience. All households offer labor services to entrepreneurs producing intermediate output. Households consume final goods and derive utility from housing services. Patient households save in the form of deposits kept at commercial banks that grant loans to entrepreneurs and offer loans on the interbank market. It is assumed that all impatient borrowers have subprime characteristics: they borrow from a subprime lender against housing collateral. ${ }^{8}$ The collateral constraints faced by borrowers determine the amount they can borrow from the bank, while bankers set the interest rates on loans, taking into account different borrowing constraints and default probabilities. The debt contracts in the economy are written in nominal terms, as in Iacoviello (2005). The financial connections of the agents are shown in Figure 3. There is a central bank in the economy implementing a Taylor rule and choosing the interest rate on deposits. Retailers, who produce a final good out of the intermediary good, are the source of nominal stickiness in the economy.

\subsection{Patient Households: Savers}

The problem of patient households ('savers') is identical to the one in Iacoviello (2005) with one difference: instead of providing loans to households and entrepreneurs, they save in the form of one-period deposits held at banks. Patient households consume, work and accumulate housing. Their optimization problem and the First Order Conditions (FOCs) are presented in Appendix E.1.

\subsection{Impatient Households: Subprimers}

Impatient households are borrowers in the model economy. The feature that distinguishes them from impatient households modeled in Iacoviello (2005) is that they may default on their loan obligation, with the default rate sensitive to house prices, which reflects the adjustable-rate feature observed in the data.

Impatient subprime households have the following utility function:

$$
\max _{b_{t}^{\text {Sub }}, h_{t}^{\text {Sub }}, L_{t}^{\text {Sub }}} E_{0} \sum_{t=0}^{\infty} \beta^{S u b, t}\left(\log c_{t}^{\text {Sub }}+j_{t} \log h_{t}^{\text {Sub }}-\frac{L_{t}^{S u b \eta^{\text {Sub }}}}{\eta^{\text {Sub }}}\right),
$$

\footnotetext{
${ }^{8}$ Previous versions of the paper (Grodecka, 2013, Grodecka, 2014, chapter 1 in Grodecka, 2015) included also the existence of prime borrowers who may borrow for long-term and do not default on their loan obligations. The existence of prime borrowers has a quantitative impact on the results of the paper (it dampens the responses to the shocks shown in the paper), but does not change them qualitatively. Given the complexity of the paper and the fact that this feature is not crucial for the paper's main result, in this version of the paper I leave the discussion of prime borrowers out.
} 


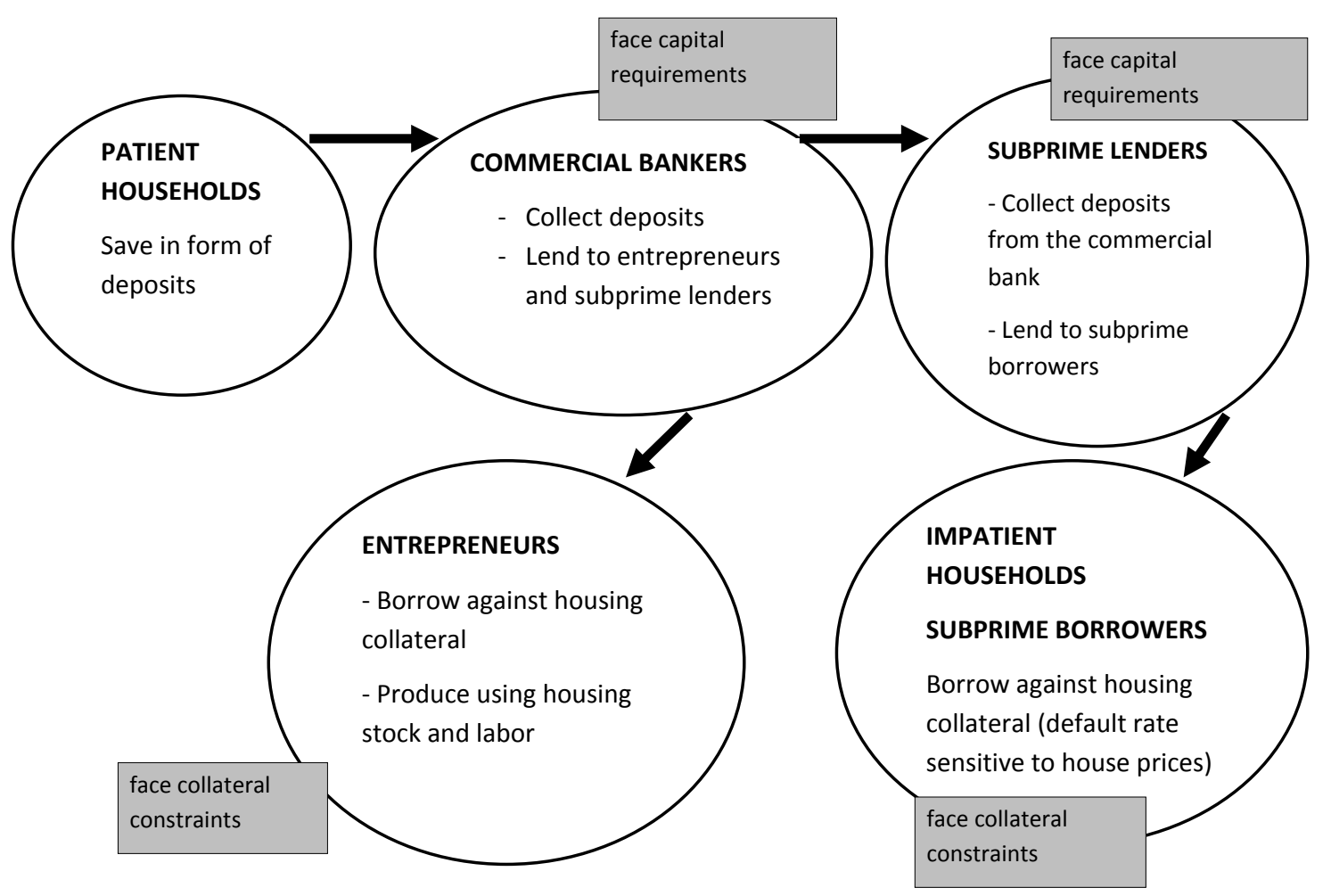

Figure 3: Financial connections in the benchmark model

where $c_{t}^{S u b}$ denotes the subprimers' consumption of the final good, $j_{t}$ is the marginal utility of housing subject to random disturbances (following Iacoviello, the disturbance is common to patient and impatient households, and is a proxy for a housing demand or housing preference shock), $h_{t}^{\text {Sub }}$ is the housing stock held by subprime households, $L_{t}^{S u b}$ denotes labor supply of impatient subprime households. The budget constraint of the impatient subprime household in real terms is:

$$
c_{t}^{S u b}+q_{t}\left(h_{t}^{S u b}-h_{t-1}^{S u b}\right)+\left(1-\delta_{s, t}\right) R_{s, t-1} b_{t-1}^{S u b} / \pi_{t}=b_{t}^{S u b}+w_{t}^{S u b} L_{t}^{S u b}
$$

where $R_{s, t}$ is the nominal interest rate on subprime loans $b_{t}^{S u b}, q_{t}=Q_{t} / P_{t}$ denotes the real housing price, $\pi_{t}=P_{t} / P_{t-1}$ is inflation and

$$
\delta_{s, t}=\delta_{s}-\phi_{s, h}\left(q_{t}-Q\right)
$$

is the default rate on loans ( $\delta_{s}$ denotes the positive steady state value of default rate, $\mathrm{Q}$ is the steady state value of housing prices, ${ }^{9} \phi_{s, h}$ denotes subprimers' default sensitivity to house price changes). The dependence on house prices is chosen to capture the high sensitivity of the hy-

\footnotetext{
${ }^{9}$ The price level in the steady state (P) equals 1 .
} 
brid subprime mortgage contract to changes in housing prices and its gamble characteristics. ${ }^{10}$ Subprime lenders bet on an increase in house prices because they may then expect a lower than predicted default rate and thus, faster repayment of the loan. ${ }^{11}$ Note that the debt contracts in this model are written in nominal terms (following Iacoviello, 2005), which reflects the majority of loan contracts in low-inflation countries.

Impatient households may borrow against the future value of their housing collateral:

$$
R_{s, t} b_{t}^{S u b} \leq m^{S u b} E_{t}\left(q_{t+1} \pi_{t+1}\right) h_{t}^{S u b}
$$

where $m^{S u b}$ determines the LTV ratio for subprime borrowers.

The FOCs of subprime borrowers are presented in Appendix E.2.

It is important to note that, although the collateral constraint of subprime borrowers does not refer to their possible default, the interest rate paid on their subprime loans includes the default premium. They pay a higher interest rate reflecting their ex ante probability of default. The subprime interest rate is determined by the subprime lenders' optimization problem, see equation 3.14 .

\subsection{Entrepreneurs}

The problem of entrepreneurs is similar to that in Iacoviello (2005) with the exclusion of capital accumulation and investment conducted by firms. ${ }^{12}$ They produce intermediate output priced at $P_{t}{ }^{w}$, using housing stock and labor provided by households, and sell it to retailers. They borrow short-term to cover their expenditures, facing a collateral constraint analogous to the one faced by households. Their optimization problem and the FOCs are presented in Appendix E.3.

\subsection{Retailers}

The problem of retailers is identical to that in Iacoviello (2005). They are the source of price stickiness in the economy. I present the equations concerning the retailer sector in Appendix E.4.

\footnotetext{
${ }^{10}$ Forlati and Lambertini (2011) consider a model with risky mortgages and endogenous default rate arising from idiosyncratic shocks to households' housing investment, which is also a proxy for modeling negative home equity and its consequences. However, in their model firms do not borrow capital from financial intermediaries, so one important transmission channel of the crisis is excluded.

${ }^{11}$ Given the formulation in equation 3.3, theoretically, when a large shock occurs, the default rate can turn negative. However, the positive steady state rate of default, as well as the fact that in a log-linearized model only shocks of a small amplitude can be considered, prevent this from happening in the current setup.

12 Capital and investment were part of the model in the earlier version of this paper, Grodecka (2013), and their inclusion does not change the results qualitatively, so for simplicity reason they were left out from this analysis.
} 


\subsection{Bankers}

\subsubsection{Commercial Bankers}

Commercial bankers collect deposits from patient households and issue loans to entrepreneurs. They also provide interbank loans for subprime lenders that operate as a bank. ${ }^{13}$ Commercial bankers maximize utility from their consumption $c_{b}$ (as in Iacoviello, 2014): ${ }^{14}$

$$
\max _{c_{b, t}} E_{0} \sum_{t=0}^{\infty} \beta_{b}^{t}\left(\log c_{b, t}\right),
$$

where $\beta_{b}$ is assumed to be lower than the discount factor of patient households (necessary condition for the capital requirement to be binding - see Iacoviello, 2014).

The budget constraint of bankers is:

$$
c_{b, t}+\frac{R_{d, t-1} d_{t-1}}{\pi_{t}}+b b_{t}+b_{e, t}=d_{t}+\frac{R_{b, t-1} b b_{t-1}}{\pi_{t}}+\frac{R_{e, t-1} b_{e, t-1}}{\pi_{t}},
$$

where $R_{d, t}$ is the interest rate on deposits $d_{t}, b b_{t}$ denotes interbank lending and $R_{b, t}$ is the interbank interest rate, $b_{e, t}$ are the loans to entrepreneurs and $R_{e, t-1}$ is the interest rate on corporate loans.

The commercial banker's balance sheet looks as follows:

\begin{tabular}{l|l}
\hline Assets & Liabilities \\
\hline Interbank loans: $b b_{t}$ & Deposits $d_{t}$ \\
Loans to entrepreneurs: $b_{e, t}$ & Equity $e q_{t}$
\end{tabular}

Thus, a Basel-type capital requirement, given exogenously, has the form:

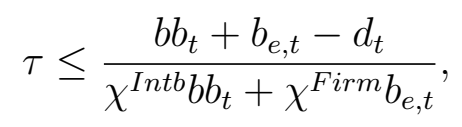

\footnotetext{
${ }^{13}$ The distinction between commercial and subprime bankers is not necessary for the benchmark version of the model, but becomes important once securitization is introduced into the model economy. The evidence from the U.S. suggests that there were several banks and financial intermediaries that specialized specifically in the subprime market.

${ }^{14}$ Note that this formulation considers a risk-averse banker. Although financial intermediaries are often considered to be risk-neutral, there is some evidence of their risk-aversion (see Ratti, 1980 and Angelini, 2000). More recently, examining interest rates for different deposit maturities for a set of U.S. banks, Nishiyama (2007) concludes that individual banks' relative risk aversion coefficients fall between 0 and 1 (most likely around 0.2 ), which means that they are slightly risk averse. The log-utility function is characterized by the decreasing absolute risk aversion and constant relative risk aversion of order 1, it is thus higher than the estimates of Nishiyama (2007). However, in the current setup the degree of risk-aversion does not matter. As the model is solved using the log-linearization technique, it has the feature of certainty equivalence: what matters for the solution are the first order-moments of variables, but not higher-order moments, such as variance. Since uncertainty does not play a role under the first-order-approximation, the solution of the model would not change if I assumed the risk-neutrality of bankers.
} 
where $\chi^{\text {Intb }}<\chi^{\text {Firm }}$ are risk weights of assets and $\tau$ denotes an equity ratio set by a regulator. The condition states that the ratio of equity (defined as assets minus deposits) to risk weighted assets has to exceed some exogenously chosen number.

The FOCs of the bankers' problem determine the interest rates paid on deposits and different types of loans ( $G_{t}$ denotes the Lagrangian multiplier on the capital requirement):

w.r.t. $b b_{t}$

$$
\frac{1}{c_{b, t}}=\beta_{b} E_{t}\left(\frac{R_{b, t}}{c_{b, t+1} \pi_{t+1}}\right)+\left(1-\tau \chi^{I n t b}\right) G_{t},
$$

w.r.t. $b_{e, t}$

$$
\frac{1}{c_{b, t}}=\beta_{b} E_{t}\left(\frac{R_{e, t}}{c_{b, t+1} \pi_{t+1}}\right)+\left(1-\tau \chi^{F i r m}\right) G_{t}
$$

w.r.t. $d_{t}$

$$
\frac{1}{c_{b, t}}=\beta_{b} E_{t}\left(\frac{R_{d, t}}{c_{b, t+1} \pi_{t+1}}\right)+G_{t}
$$

The interpretation of equations 3.8 to 3.10 is crucial for understanding the main result of the paper. The equations without considering the Lagrangian multiplier on the capital requirement represent typical Euler equations, saying that the banker must be indifferent between consuming one unit of consumption today, and lending one unit today and consuming it tomorrow. The capital requirement of bankers introduces a wedge between the cost and marginal gain from lending. Its bindingness influences the bankers' decisions between consumption and borrowing/lending and gives rise to the process of deleveraging. This results in a shrinking balance sheet in the face of a negative shock, as bankers are impatient and prefer to consume rather than raise equity or increase their lending.

\subsubsection{Subprime Lenders}

Subprime lenders operate as financial intermediaries that collect deposits $b b_{t}$ from the interbank market and issue subprime loans $b_{t}^{S u b}$.

Their optimization problem is:

$$
\max _{c_{b b, t}} E_{0} \sum_{t=0}^{\infty} \beta_{b b}^{t}\left(\log c_{b b, t}\right)
$$

s.t.

$$
c_{b b, t}+b_{t}^{S u b}+R_{b, t-1} b b_{t-1} / \pi_{t}=b b_{t}+R_{s, t-1}\left(1-\delta_{s, t}\right) b_{t-1}^{S u b} / \pi_{t},
$$

where $c_{b b, t}$ denotes subprime lenders' consumption. I assume that subprime lenders hold a reserve for future losses, taking into account the ex ante (steady state) default rate. The subprime banker's balance sheet is: 


\begin{tabular}{l|l}
\hline Assets & Liabilities \\
\hline Loans to subprime borrowers: $b_{t}^{\text {Sub }}$ & Interbank deposits $b b_{t}$ \\
Loss reserve $-\delta_{s} b_{t}^{\text {Sub }}$ & Equity $e q_{t}$
\end{tabular}

Thus, a Basel-type capital requirement, given exogenously, has the form:

$$
\tau^{S u b} \leq \frac{\left(1-\delta_{s}\right) b_{t}^{S u b}-b b_{t}}{\chi^{S u b}\left(1-\delta_{s}\right) b_{t}^{S u b}}
$$

where the risk weight on subprime loans is denoted by $\chi^{S u b}$ and $\tau^{S u b}$ is the capital ratio imposed on subprime lenders by the regulator.

The FOCs of the subprime bankers' problem $\left(G G_{t}\right.$ denotes the Lagrangian multiplier on the capital requirement of subprime lenders) are:

w.r.t. $b_{t}^{\text {Sub }}$

$$
\frac{1}{c_{b b, t}}=\beta_{b b} E_{t}\left(\frac{R_{s, t}\left(1-\delta_{s, t+1}\right)}{c_{b b, t+1} \pi_{t+1}}\right)+\left(1-\tau^{S u b} \chi^{S u b}\right)\left(1-\delta_{s}\right) G G_{t}
$$

w.r.t. $b b_{t}$

$$
\frac{1}{c_{b b, t}}=\beta_{b b} E_{t}\left(\frac{R_{b, t}}{c_{b b, t+1} \pi_{t+1}}\right)+G G_{t} .
$$

Equation 3.14 determines the interest rate paid on subprime loans and makes clear that when pricing the subprime loan, the subprime lender takes into account the default probability of the borrowers. As a consequence, the steady state interest rate on subprime loans is higher than that of loans with a zero default probability.

\subsection{Central Bank}

The central bank implements a Taylor type interest rate rule (identical to Iacoviello, 2005). It is assumed that the interest rate set by the central bank equals the interest rate paid on deposits (disregarding reserve requirements):

$$
R_{d, t}=\left(R_{d, t-1}\right)^{r_{R}}\left(\pi_{t-1}^{1+r_{\pi}}\left(\frac{Y_{t-1}}{Y}\right)^{r_{y}} \overline{r r}\right)^{1-r_{R}} e^{e_{R, t}}
$$

\subsection{Market Clearing Conditions}

Following Iacoviello (2005), I assume that real estate is fixed in the aggregate. The market clearing condition for the housing market is:

$$
1=h_{t}^{\text {Savers }}+h_{t}^{\text {Sub }}+h_{e, t} .
$$


The goods market clearing condition is given by:

$$
Y_{t}=c_{t}^{\text {Savers }}+c_{t}^{\text {Sub }}+c_{e, t}+c_{b, t}+c_{b b, t} .
$$

The market clearing conditions for labor are defined by equations E.5 and E.15 for the patient households' labor supply and demand, and by equations E.8 and E.16 for the impatient subprime households. The lending to different agents is determined through their collateral constraints, while the market clearing conditions for the loan and deposits markets are given by the capital requirements of the bankers (equation 3.7 and 3.13).

\section{Model with Securitization of Subprime Loans}

The data provides evidence for the importance of securitization in subprime lending. The majority of subprime loans have been securitized, first in the form of a RMBS, which often was a building block of CDO structures. Usually, different subprime borrowers have different default probabilities, so securitization may be a way to average the risk on subprime exposure. In the present model, all subprime borrowers have the same default rate, which can be interpreted as a default rate representing the mean of the aggregate distribution over all subprime borrowers, who differ in their default sensitivity at an individual level. Typically, an MBS structure consists of three tranches: senior, mezzanine and equity. To simplify the computation, I assume that the model's RMBS consists only of two tranches: senior and equity. Figure 4 illustrates the payoff functions of investors in the RMBS.

Face value of MBS:

$$
S_{t}=R_{s, t-1} B_{t-1}^{S u b}
$$

\begin{tabular}{|c|c|}
\hline $\begin{array}{c}\text { Senior tranche } \\
\text { A rated }\end{array}$ & $\begin{array}{l}\text { Payoff of the senior tranche } \\
P_{s, t}=\min \left(S_{t}-f S_{t}, S_{t}-\operatorname{Loss}_{t}\right)\end{array}$ \\
\hline $\begin{array}{l}\text { Equity tranche } \\
\text { C rated }\end{array}$ & $\begin{array}{l}\text { Attachment point } \mathbf{f} \\
\text { Payoff of the equity tranche } \\
\qquad P_{e, t}=\max \left(f S_{t}-\operatorname{Loss}_{t}, 0\right)\end{array}$ \\
\hline
\end{tabular}

Figure 4: A two-tranche MBS (face value written in nominal terms)

The security is a pass-through security, which means that the nominal loan proceeds are redistributed to the MBS investors. The smaller the loss on the underlying loan portfolio (de- 
termined by the default rate), the larger is the payoff of equity tranche investors. The size of the equity tranche, determined by the parameter $f$, called the attachment point in the CDO jargon, defines the maximum risk exposure of equity tranche investors. ${ }^{15}$ If there is a loss on the underlying loan portfolio, the equity tranche investors get the difference between the size of the equity tranche and the loss. However, if the loss exceeds the size of the tranche, the equity tranche investors simply get nothing from their investment, and the senior tranche investors begin to suffer. Their payoff function is a minimum function. They either get back the tranche size, or the difference between the face value of the MBS and the loss (in the case where losses are bigger than the size of the equity tranche). $P_{s, t}=\min \left(S_{t}-f S_{t}, S_{t}-\right.$ Loss $\left._{t}\right)$ denotes the payoff of senior tranche buyers, and $P_{e, t}=\max \left(f S_{t}-\operatorname{Loss}_{t}, 0\right)$ denotes the payoff of equity tranche buyers, where the principal of the MBS is (in real terms) $S_{t}=R_{s, t-1} b_{t-1}^{S u b} / \pi_{t}$, and loss equals $\delta_{s, t} S_{t} \cdot{ }^{16}$

To quantify the importance of the engagement of commercial banks in the securitization process, I consider two cases. In the first case, I assume that the generated MBS tranches are bought by patient households (because they are more patient, they acquire claims on the senior tranche) and entrepreneurs (because of their degree of impatience, they are more prone to acquire claims on the equity tranche). In the second case, I assume that the commercial bankers buy the senior tranche of MBS and the entrepreneurs invest in the equity tranche. ${ }^{17}$ In both cases, subprime lenders retain a vertical fraction $t$ of the issued security (equivalent to retaining a percentage $t$ of cash flows). ${ }^{18}$

Why might commercial bankers buy claims on MBS? One reason may be the diversification of their credit risk and the exposure to a different credit market. Also, they may be as optimistic as subprime borrowers are, and believe that housing prices will continue to rise. Moreover,

\footnotetext{
${ }^{15}$ Gorton (2008) argues that subprime securitization differs from the securitization of other assets because the tranche sizes are not fixed. There is dynamic tranching as a function of excess spread and prepayments, so the whole structure is sensitive to house prices. At the beginning of the existence of a subprime MBS, the equity tranches are usually very thin and along with repayments of the subprime loans they reach their target level. However, if house prices decline from the very beginning, the equity tranche remains very thin and thus senior tranche holders are subject to a very large subprime risk (that was the case for MBS issued in 2006 and later). This works as another amplification mechanism in the design of subprime security. Including varying tranche sizes in the model would thus amplify the effects of shocks in the economy.

${ }^{16}$ The payoffs of equity and senior tranche holders resemble payoffs from investment in European options. More information on the option characteristics of MBS tranches is given in Appendix F. In order to solve the model with the non-linear payoff functions for the MBS tranches, I use the piecewise linear perturbation solution as presented in Guerrieri and Iacoviello (2015). Grodecka (2015) uses the logistics approximation of the maximum function, which delivers the same qualitative and very similar quantitative results, but is less accurate.

${ }^{17}$ One could also assume that one and the same agent buys both tranches. In that case, the conclusions of the paper hold: if only non-financial agents in the economy buy MBS tranches, securitization results in a dampending of business cycles, but whenever also commercial banks buy MBS tranches, securitization results in an amplification of business cycles.

${ }^{18}$ In general, the literature discusses three main types of retention: vertical slice retention, horizontal slice retention, and an equivalent exposure of the securitized pool, discussed further in Geithner (2011). In the present model's case, vertical slice retention generates the same payoff for the bank as equivalent exposure.
} 
senior tranches usually have the highest possible rating, so the risk weight on them is very low and the purchase has a positive impact on the balance sheet of banks. The regulatory capital arbitrage is the reason why subprime lenders may want to conduct securitization and why commercial bankers may want to buy certain tranches, as described in Jones (2000). Why might patient households and entrepreneurs buy MBS tranches? For them, this investment is just another possibility to smooth their consumption. It is reasonable to assume that other agents than banks were mostly exposed to losses on equity tranches of MBS, given that the residual tranches of securitized assets had much larger risk-weights than the senior tranches after the introduction of the so-called 'recourse rule' by Fed in 2001. As such, banks had much more incentives to hold senior MBS tranches.

I assume that certain agents in the economy invest in MBS securities, and I do not model their decision as a portfolio choice decision, which allows me to use the first order approximation to solve the model. ${ }^{19}$ For answering the research question of this paper this approach is sufficient, as I do not aim to explain how the securitized assets were distributed among the investors.

Securitization changes the capital requirement faced by originators of the subprime loans, as they may remove part of the risk from the balance sheet due to the repackaging and sale of the assets. In the case of entrepreneurs and patient households who buy MBS tranches, their budget constraint changes to include the new asset acquired, and the FOC with respect to the new asset determines its price. When commercial bankers invest in MBS tranches, apart from a changed budget constraint, the capital requirement of the bankers also changes in order to include the new asset into the balance sheet of the investor. The following subsections 4.1 and 4.2 present the equation that are changed in the model with securitization with respect to the bechmark model presented in section 3. If not stated otherwise, all remaining equations remain exactly the same as in the benchmark model.

\subsection{First Version: Patient Households and Entrepreneurs Invest in MBS Tranches}

In the first version of the model with securitization of subprime loans, patient households invest in the senior tranche, and entrepreneurs in the equity tranche.

The budget constraints of investors change and a new term describing investment in the derivative security appears. First, denote the payoff of the senior tranche $E_{t}\left[\min \left(S_{t+1}-\right.\right.$ $\left.\left.f S_{t+1}, S_{t+1}-\delta_{s, t+1} S_{t+1}\right)\right]$ as $M B S_{s, t}$ and the price of the senior tranche by $p_{s, t}$. Then, the budget constraint of the patient household is (remember that subprime lenders retain portion $t$

\footnotetext{
${ }^{19}$ For the determination of the portfolio choice, higher-order solutions have to be used, as under the first order approximation, the equilibrium portfolio is not determined (Devereux and Sutherland, 2010).
} 
of every tranche):

$$
\begin{aligned}
& c_{t}^{\text {Savers }}+q_{t}\left(h_{t}^{\text {Savers }}-h_{t-1}^{\text {Savers }}\right)+d_{t}+(1-t) p_{s, t} M B S_{s, t}= \\
& R_{d, t-1} d_{t-1} / \pi_{t}+w_{t}^{\text {Savers }} L_{t}^{\text {Savers }}+F_{t}+(1-t) M B S_{s, t-1} .
\end{aligned}
$$

In each period, the patient household gets revenue from investing in the senior tranche and buys a claim on future proceedings from investment in MBS. The FOCs of prime households do not change, but there is a new equation determining the price of the new claim:

$$
\beta \frac{1}{c_{t+1}^{\text {Savers }}}=p_{s, t} \frac{1}{c_{t}^{\text {Savers }}}
$$

Analogously, denote the terms describing the investment in the equity tranche $E_{t}\left[\max \left(f S_{t+1}-\right.\right.$ $\left.\left.\delta_{s, t+1} S_{t+1}, 0\right)\right]$ as $M B S_{e, t}$ and $\max \left(f S_{t}-\delta_{s, t} S_{t}, 0\right)$ as $M B S_{e, t-1}$ and the price of the equity tranche by $p_{e, t}$. Then, the budget constraint of the entrepreneur is:

$$
\begin{aligned}
& \frac{Y_{t}}{X_{t}}+b_{e, t}+(1-t) M B S_{e, t-1}= \\
& c_{e, t}+q_{t}\left(h_{e, t}-h_{e, t-1}\right)+\frac{R_{e, t-1}}{\pi_{t}} b_{e, t-1}+w_{t}^{\text {Savers }} L_{t}^{\text {Savers }}+w_{t}^{\text {Sub }} L_{t}^{\text {Sub }}+(1-t) p_{e, t} M B S_{e, t} .
\end{aligned}
$$

The FOC w.r.t to the new claim is:

$$
\gamma \frac{1}{c_{e, t+1}}=p_{e, t} \frac{1}{c_{e, t}} .
$$

Along with the optimization problems of agents investing in the security, the problem of subprime lenders also changes in the wake of securitization of subprime loans. They have now to include only the retained proportion of subprime loans in their balance sheet:

\begin{tabular}{l|l}
\hline Assets & Liabilities \\
\hline Loans to subprime borrowers: $t b_{t}^{\text {Sub }}$ & Interbank deposits $b b_{t}$ \\
Loss reserve $-t \delta_{s} b_{t}^{\text {Sub }}$ &
\end{tabular}

Thus, a Basel-type capital requirement, given exogenously, is now given by:

$$
\tau^{S u b} \leq \frac{t\left(1-\delta_{s}\right) b_{t}^{S u b}-b b_{t}}{\chi^{S u b} t\left(1-\delta_{s}\right) b_{t}^{S u b}} .
$$

The budget constraint of subprime lenders changes. Note that when it comes to the transfer of already realized cashflows, it holds that: 
$(1-t)\left[\min \left(S_{t}-f S_{t}, S_{t}-\delta_{s, t} S_{t}\right)+\max \left(f S_{t}-\delta_{s, t} S_{t}, 0\right)\right]=(1-t)\left[S_{t}\left(1-\delta_{s, t}\right)\right]=(1-t)\left[R_{s, t-1} b_{t-1}^{S u b}(1-\right.$ $\left.\left.\delta_{s, t}\right) / \pi_{t}\right]$. Yet, in the case of claims purchases on future proceedings, this shortcut cannot be made because the prices of both tranches differ, since the agents that buy them have different discount factors. Thus, the budget constraint of the subprime lender is:

$$
\begin{aligned}
c_{b b, t}+b_{t}^{S u b}+R_{b, t-1} b b_{t-1} / \pi_{t}-(1-t)\left[p_{s, t} M B S_{s, t}+\right. & \left.p_{e, t} M B S_{e, t}\right]= \\
& b b_{t}+t R_{s, t-1}\left(1-\delta_{s, t}\right) b_{t-1}^{S u b} / \pi_{t} .
\end{aligned}
$$

The prices of the tranches are determined by equations 4.20 and 4.22 .

\subsection{Second Version: Commercial Bankers and Entrepreneurs Invest in MBS Tranches}

In the second version of the model with securitization, commercial bankers invest in the senior tranche, whereas entrepreneurs, as in the first case, buy claims on the equity tranche. The problem of the entrepreneurs does not change with respect to the version of the model when patient households and entrepreneurs buy MBS tranches. The budget constraint of commercial bankers changes, as well as their balance sheet and capital requirement. I assume here that the risk weight on the senior tranche is as high as in the case of interbank deposits (since it is highly rated), whereas the risk weight on the equity tranche equals the risk weight of subprime loans.

The commercial bankers' balance sheet is:

\begin{tabular}{l|l}
\hline Assets & Liabilities \\
\hline Interbank loans : $b b_{t}$ & Deposits $d_{t}$ \\
Loans to entrepreneurs: $b_{e, t}$ & Equity $e q_{t}$ \\
MBS security - senior tranche: $(1-t) M B S_{s, t}$ &
\end{tabular}

Thus, a Basel-type capital requirement, given exogenously, has the form:

$$
\tau \leq \frac{b b_{t}+b_{e, t}+(1-t) M B S_{s, t}-d_{t}}{\chi^{\text {Intb }} b b_{t}+\chi^{F i r m} b_{e, t}+\chi^{I n t}(1-t) M B S_{s, t}} .
$$

The budget constraint of commercial bankers is now:

$$
\begin{aligned}
& c_{b, t}+R_{d, t-1} d_{t-1} / \pi_{t}+b b_{t}+b_{e, t}+(1-t) p_{s, t} M B S_{s, t}= \\
& d_{t}+R_{b, t-1} b b_{t-1} / \pi_{t}+R_{e, t-1} b_{e, t-1} / \pi_{t}+(1-t) M B S_{s, t-1} .
\end{aligned}
$$


New FOC:

w.r.t. $M B S_{s, t}$

$$
\beta_{b} \frac{1}{c_{b, t+1}}=p_{s, t} \frac{1}{c_{b, t}}+\left(1-\tau \chi^{\text {Int }}\right) G_{t} .
$$

The problem of subprime lender is analogous to the case where patient households and entrepreneurs buy MBS tranches.

\section{Calibration and Results}

\subsection{Calibration}

The model is log-linearized around the steady state. The log-linearized equations present variables in the form of percent deviations from the steady state, which makes the interpretation of model variables easier. For the versions of the model with securitization (presented in the section 4.1 and 4.2), I use the "occbin" toolkit presented in Guerrieri and Iacoviello (2015) applying a piecewise linear perturbation solution. All equations describing the benchmark model (also shock processes) are given in Appendix E.5. ${ }^{20}$ I calibrate the model using parameter values from the literature, as well as empirical papers (see Table 1).

Following Iacoviello (2005), I assume that patient households have the highest discount factor, followed by entrepreneurs and both types of bankers. The most impatient agents in the economy are subprime borrowers. The choice of discount factors assures that the collateral constraints in the model are always binding. The parameter $J$ controls the stock of residential housing over annual output in the steady state, $J=0.09$ fixes this ratio around $150 \%$, which is in line with the data from the Flow of Funds accounts (table B.100, row 4). The LTV ratios for firms and subprime borrowers are set at 0.99 , which is a high value, but is consistent with the literature (Iacoviello, 2014). Parameter $\eta$ is chosen to fix the Frisch labor supply elasticity at 1 . The chosen value lies between the estimates provided by microeconomic studies $(0-0.54)$ and by macroeconomic studies (2-4) (see Peterman, 2012). The steady state gross markup is a value taken from Iacoviello (2005). The patient households' wage share of 0.87 corresponds to the conclusions of Jappelli (1990) who finds that $19 \%$ of U.S. families are rationed in credit markets and they account for $12.7 \%$ of total wage income. The value of 0.55 for the parameter $\theta$ describing the price rigidity is consistent with the evidence of Dhyne et al. (2006) who show that the average price duration in the United States equals 6.7 months.

\footnotetext{
${ }^{20}$ A list of the log-linearized equations for the extended version of the model (including capital and investment, as well as impatient prime borrowers), may be found in the previous working paper version of this model, Grodecka (2013).
} 


\begin{tabular}{lll}
\hline Description & Parameter & Value \\
\hline Discount factor of patient households & $\beta$ & 0.995 \\
Discount factor of impatient households & $\beta^{S u b}$ & 0.93 \\
Discount factor of entrepreneurs & $\gamma$ & 0.96 \\
Discount factor of commercial bankers & $\beta_{b}$ & 0.97 \\
Discount factor of subprime lenders & $\beta_{b b}$ & 0.95 \\
Weight on housing services & $J$ & 0.09 \\
Loan to value entrepreneurs & $m$ & 0.99 \\
Loan to value subprime households & $m^{\text {Sub }}$ & 0.99 \\
Labor supply aversion & $\eta^{\text {Savers }}=\eta^{S u b}$ & 2 \\
Housing share in production function & $\nu$ & 0.15 \\
Steady state gross markup & $X$ & 1.05 \\
Patient households wage share & $\alpha$ & 0.87 \\
Probability fixed price & $\chi^{S u}$ & 0.55 \\
Capital adjustment costs & $\phi$ & 2 \\
Risk weight of interbank loans & $\chi^{I n t b}$ & 0.2 \\
Risk weight on commercial loans & $\chi^{F i r m s}$ & 1.5 \\
Risk weight of subprime loans & $\chi^{S u b}$ & 4.5 \\
Commercial bankers capital requirement & $\tau$ & 0.13 \\
Subprime lenders capital requirement & $\tau^{S u b}$ & 0.2 \\
Subprimers' default sensitivity to house price changes & $\phi_{s h}$ & 0.183 \\
Steady state subprime default rate & $\delta_{s}$ & 0.05 \\
Weight of policy response to interest rate & $r_{R}$ & 0.73 \\
Weight of policy response to inflation & $r_{\pi}$ & 0.27 \\
Weight of policy response to output & $r_{y}$ & 0.13 \\
Autocorrelation of preference shock & $\rho_{j}$ & 0.95 \\
Standard deviation of preference shock & $\sigma_{\varepsilon_{j}}$ & 1 \\
Standard deviation of monetary shock & $\sigma_{\varepsilon_{R}}$ & 1 \\
Tranche retention by banks & $t$ & 0.01 \\
Attachment point of senior tranche & $f$ & 0.2 \\
\hline
\end{tabular}

Table 1: Calibrated parameters 
Parameters describing the risk weights of different types of loans are based on U.S. regulations of the Federal Deposit Insurance Corporation (Code of Federal Regulations - Title 12: Banks and Banking, 12 CFR Appendix A to Part 325 - Statement of Policy on Risk-Based Capital). Interbank loans have the lowest risk weight, followed by the risk weight on commercial loans (the factor for risky loans has been applied). The risk weight on subprime loans has a very high value, which is consistent with the Expanded Guidance for Subprime Lending Programs, ${ }^{21}$ stating "that an institution would hold capital against subprime portfolios in an amount that is one and a half to three times greater than what is appropriate for non-subprime assets of a similar type". The capital ratio for commercial bankers corresponds to the average regulatory capital to risk-weighted assets for the United States before the crisis, reported in the FRED database. ${ }^{22}$ The capital ratio for subprime lenders is higher than for commercial bankers, which again, corresponds to the Expanded Guidance for Subprime Lending Programs: "Institutions with subprime programs affected by this guidance should have capital ratios that are well above the averages for their traditional peer groups or other similarly situated institutions that are not engaged in subprime lending. (...) institutions that underwrite higher-risk subprime pools, such as unsecured loans or high loan-to-value second mortgages, may need significantly higher levels of capital, perhaps as high as $100 \%$ of the loans outstanding depending on the level and volatility of risk".

The sensitivity of subprime households to housing price changes has been chosen according to the pre-crisis data. Over time, the sensitivity changed and it was much higher just before the outbreak of the crisis, but on average one can assume that it did not exceed 20\% (Amromin and Paulson, 2010). The subprime default rate is chosen to be $5 \%$ in the steady state. According to the data presented in Demyanyk and Hemert (2011), in the decade preceding the crisis, the default rate on subprime hybrid loans oscillated around 10\%. However, usually when a household defaults on its mortgage, the bank seizes and sells the property, receiving some foreclosure value. The present model does not have this feature, thus the steady state default rate is half of that in the data. Also, a higher steady state default rate would result in an unreasonably high steady state value for the interest rate on subprime loans. The Taylor rule coefficients are taken from Iacoviello (2005). The shocks are assumed to be persistent, with the autocorrelation coefficient equal to 0.95 . I consider a 1 percent shock in each case. For the parameters governing the securitization process, evidence suggests that on average, retention of securitized assets is higher in Europe than in the U.S. Whereas originators usually held around $5 \%$ of issued securities in Europe, the retention rate was often at $0 \%$ and rarely exceeded $1 \%$ for MBS in the U.S. Retention percentages for CDOs and ABS (Asset Backed Securities) were usually higher, but in the years 2002-2009, on average they did not exceed 7\% (Global Financial

\footnotetext{
${ }^{21}$ http://www.federalreserve.gov/boarddocs/srletters/2001/sr0104al.pdf

${ }^{22}$ Series DDSI05USA156NWDB
} 
Stability Report, October 2009, p. 100-107).

\subsection{Model Dynamics}

I consider two shocks: monetary and preference. ${ }^{23}$ The monetary shock is defined as an exogenous increase in the interest rate set by the central bank and can be interpreted as a discretionary deviation from the Taylor rule. The negative preference shock represents a change in the preference for housing among households. This may capture - in reduced form - a regulatory or taxation reform that makes investment in the housing market less attractive to households (regulatory reforms allowing for a large range of mortgage products could have led to a positive preference shock in the U.S., see Temkin et al., 2002).

The introduction of a subprimers' default rate sensitive to housing prices has only a negligible impact on impulse response functions to shocks in the benchmark model without securitization, so the comparison between the benchmark model with and without varying default rate is not shown in the paper. ${ }^{24}$ The varying default rate, particularly, the rising default rate after a negative shock leading to a fall in housing prices, is a positive wealth effect from the subprimers' perspective - they may repay less than contracted. Feeling wealthier, subprime borrowers will reduce their labor supply when compared to the case where the default rate does not vary, which drives output down. For subprime lenders, the rising default rate represents a negative wealth effect, because they do not get back all the contracted loan installments. Suffering losses on their loan portfolio, subprime lenders face a tighter capital requirement. They will reduce their lending to subprime borrowers and raise the interest rate on subprime loans, but their consumption will also go down. The described redistribution effect and balance sheet effect have a negative effect on overall consumption, and more responsive housing prices affect other borrowers in the economy who use housing stock as collateral for their loans. However, the subdivision of the banking sector into the subprime and the commercial segments prevents the negative developments in the subprime market from spreading to other sectors of the economy, especially the production sector which is unaffected by subprimers' defaults and no significant effect on the aggregate output can be observed.

A more interesting comparison is given in Figure 5 which presents the impulse responses for output of the benchmark model (solid blue line) and two versions of the model with securitization. Impulse responses are presented as percent deviations from the steady state. The dashed green line shows the responses of the model in which entrepreneurs buy the equity

\footnotetext{
${ }^{23}$ An earlier working paper version presenting this model (Grodecka, 2013) includes also a technology and an inflation shock. Monetary and preference shocks are the most important in explaining the main transmission mechanism, so I only focus on them.

${ }^{24}$ This result is shown and discussed more in detail in the previous working paper versions of the model, see Grodecka (2013) and Grodecka (2014).
} 


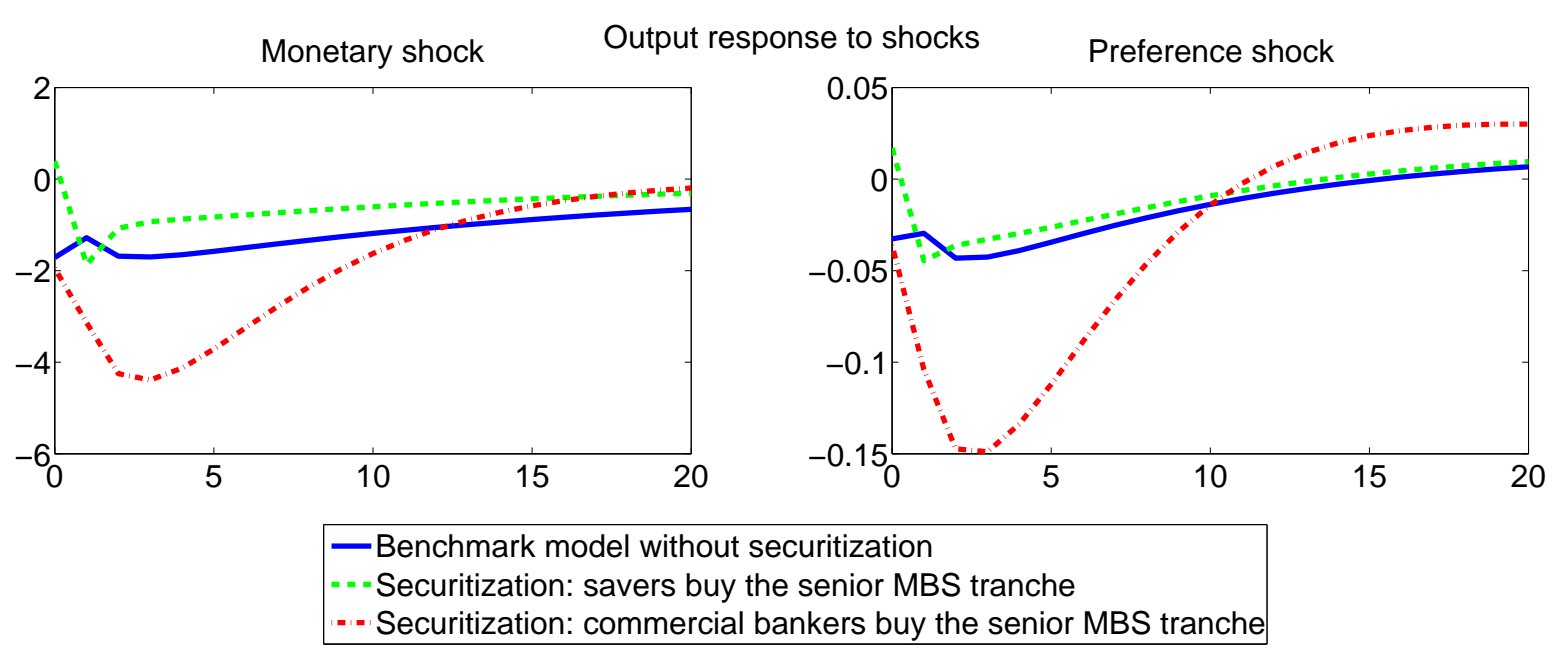

Figure 5: Output responses of model versions with and without subprime securitization

Note: All impulse responses are measured in percentage deviations from steady state

MBS tranche and the savers buy the senior MBS tranche, whereas the dashed-dotted red line shows the responses of the model in which entrepreneurs buy the equity tranche and commercial bankers buy the senior MBS tranche. In the case of both shocks, in the model, in which only non-financial agents of the economy acquire the MBS tranches (green dashed line), the output response is smaller than in the benchmark case.

Due to securitization, the capital constraint of subprime lenders becomes relatively looser (they hold less assets decreasing in value on their balance sheets, see Adrian and Shin, 2010) and their consumption is less responsive to shocks than in the benchmark model. As subprime lenders' liabilities (interbank deposits) are assets of commercial bankers, securitization, by enabling subprime lenders to sell toxic assets, will protect their balance sheets from shrinking in the case of a negative shock. The mechanism of interbank linkages is presented in Figure 6, which shows balance sheets of the subprime lender and the commercial lender (balance sheets do not necessarily have to be of the same size, as depicted in Figure 6). Before a negative shock, the balance sheets have a size depicted by the solid black line. After a negative shock, the overall lending decreases, but the deleveraging effect is different depending on who is the ultimate bearer of the securitized risk.

Through the interbank linkages, a larger (relative to the benchmark without securitization) subprime balance sheet leads, ceteris paribus, to a larger commercial bankers' balance sheet, and thus more potential lending to firms. Of course, buying claims on MBS tranches changes the budget constraints of the investors and has impacts on their consumption, but they can absorb losses on MBS through working and saving (patient households) or borrowing (entrepreneurs). The overall effect of securitization is to dampen the fall in lending and output, 
Balance sheet of subprime lender Balance sheet of commercial lender

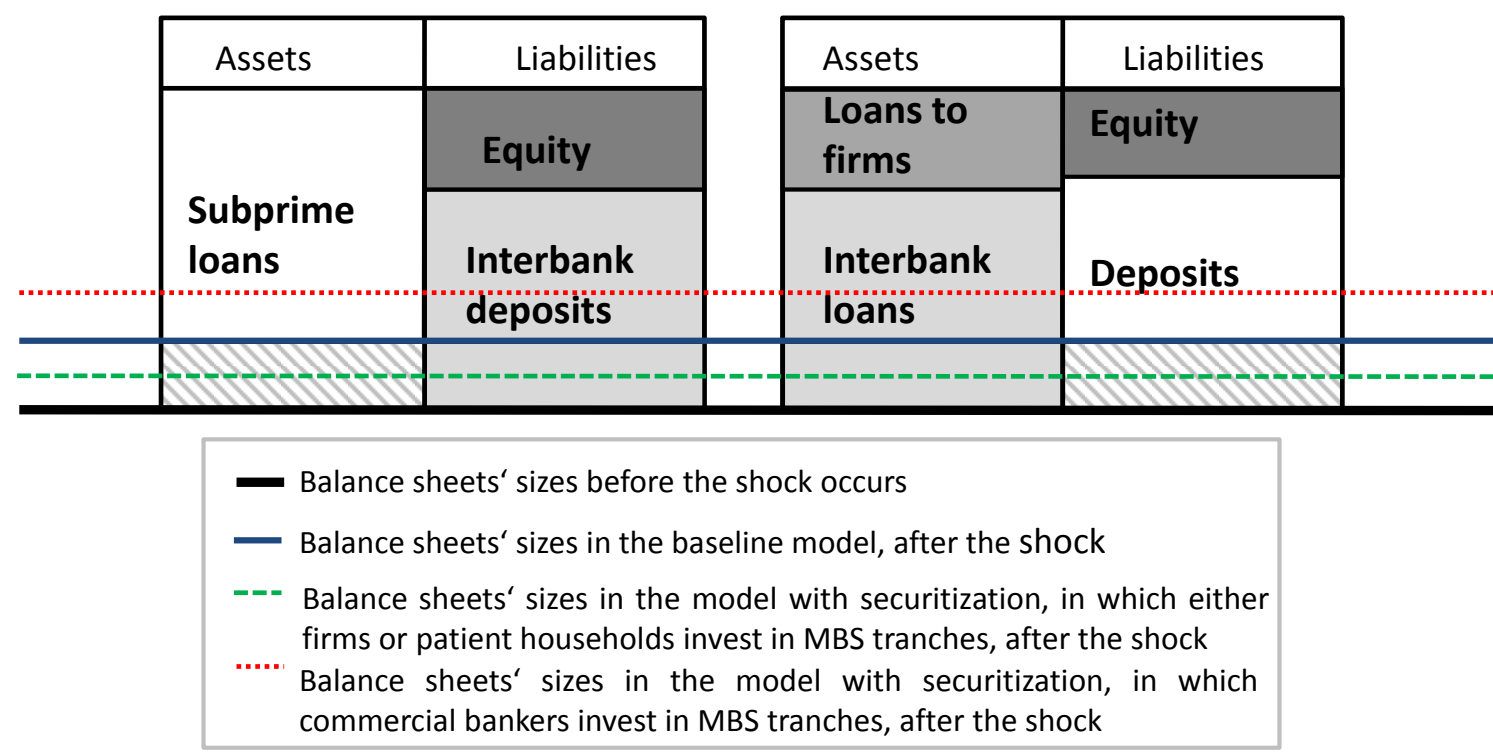

Figure 6: Interconnected balance sheets of financial intermediaries in the model

because the risk is spread among different agents in the economy. This is the way securitization was expected and is supposed to work.

However, another possibility was also considered - that commercial bankers, instead of savers, buy the senior MBS tranche. If securitized assets are bought by commercial bankers, there is an amplification of the output response after shocks. The amplification occurs not only in comparison to the version of the model in which securitized products are bought by savers and entrepreneurs, but also with respect to the benchmark model without securitization. What is the reason for this amplified contraction? All the effects occur through the balance sheets of both types of bankers. Issuing MBS makes the capital constraint of subprime lenders looser (in the case of a negative shock), whereas it tightens the capital constraint of commercial bankers because they hold the MBS (that is declining in value after a negative shock because of the increasing default rate) on their balance sheets. To reduce the tightness of the constraint, commercial bankers may either reduce their consumption or lending (a similar mechanism occurs in Iacoviello, 2014). In the present model, they do both. ${ }^{25}$

When a negative shock hits the economy and commercial bankers buy MBS tranches, their

\footnotetext{
${ }^{25}$ Why do banks tend to adjust their deposits rather than equity? As Adrian and Shin (2011) document, the equity of financial intermediaries behaves in many cases like a pre-determined variable and it is relatively sticky, which may be explained by possible non-pecuniary benefits to bank owners (new equity leads to dilution of the value of stakes of the insiders, loss of the control over shares). In the stock market context, raising new equity through issuing new shares may be difficult in times of falling asset prices. Thus, even if theoretically a financial intermediary facing an increased leverage has two options to cope with that situation, a fall in asset prices often leads to a contraction in the balance sheet.
} 


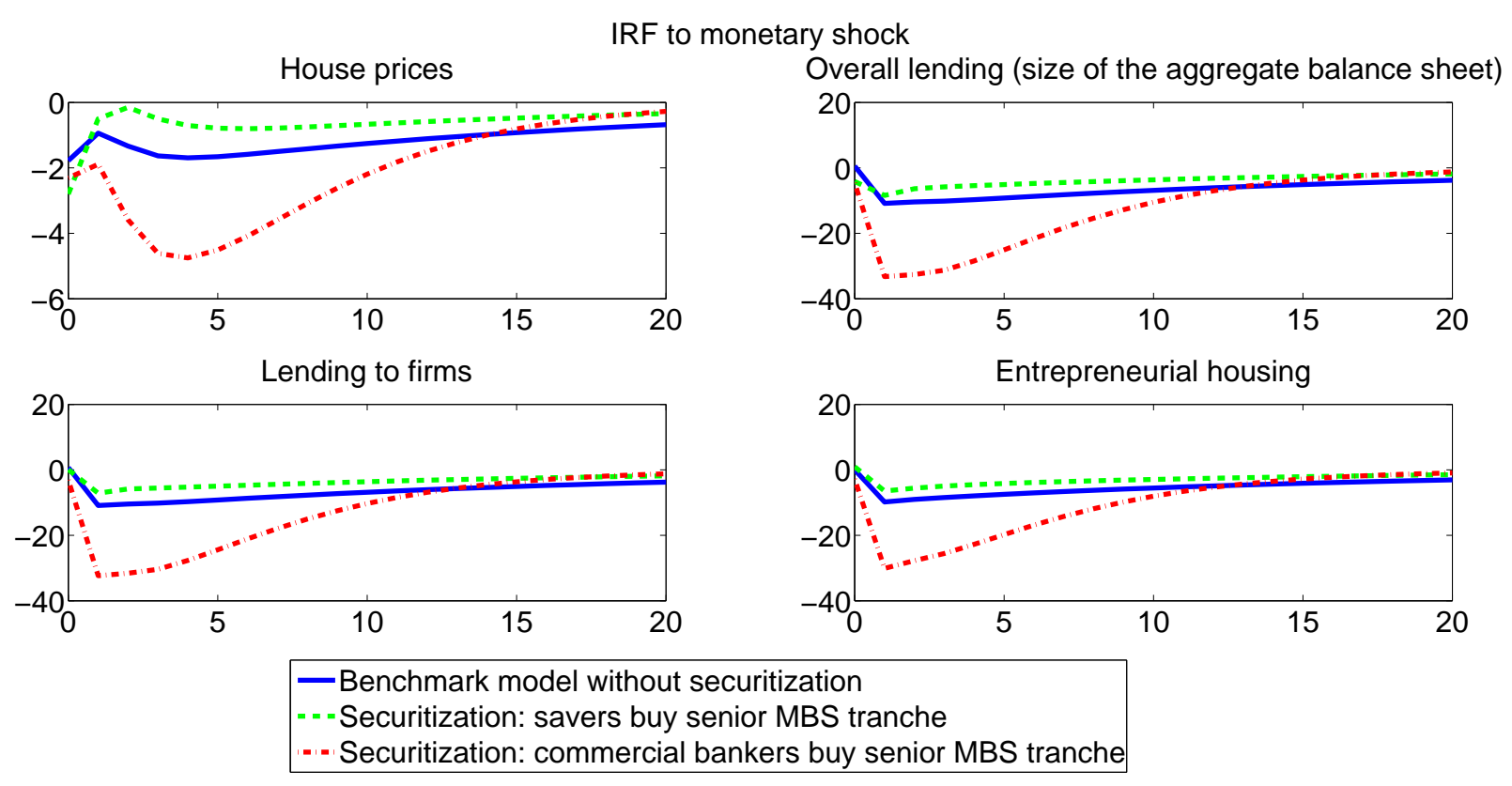

Figure 7: Impulse responses of models with and without subprime securitization

Note: All impulse responses are measured in percentage deviations from steady state

capital constraint gets tighter and they reduce the lending to entrepreneurs who finance housing stock purchases with loans from the bank. This effect is stronger in that case than when subprime losses are located on the subprime lender's balance sheet, because the leverage of commercial bankers is higher in the first place. As the housing stock is a production factor, output in the economy goes down more than without securitization. When non-banks buy MBS tranches, there is no loss on the balance sheet of commercial bankers and securitization reduces business cycle fluctuations. In the benchmark case, entrepreneurs are relatively unaffected by the defaults in the subprime sector. When commercial bankers engage in securitization, a more direct link is created between the production sector and the subprime mortgage market, so that entrepreneurs suffer from losses in the subprime portfolio more than in the benchmark case. These dynamics are visible in Figures 7 and 8 which present chosen model variables after a monetary shock and the preference shock. From Figures 7 and 8 it is visible that commercial bankers become buyers of MBS, the entrepreneurial borrowing and housing stock are considerably lower than in the benchmark case and in the case where only patient households and entrepreneurs buy MBS. Also the aggregate balance sheet represented by the overall lending sector confirms the intuition presented in Figure 6. Due to a negative shock, the lending goes down in all of the considered models, but the strength of this effect differs.

Apart from considering the impulse response functions, one can also have a look at the model's theoretical moments. Table 2 presented below shows the standard deviations of the 


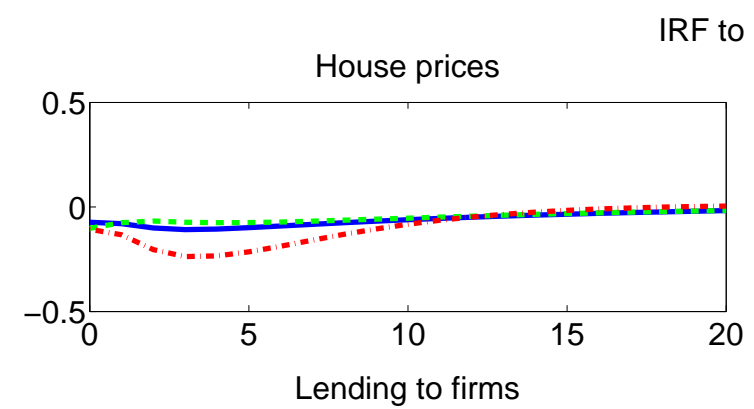

ence shock
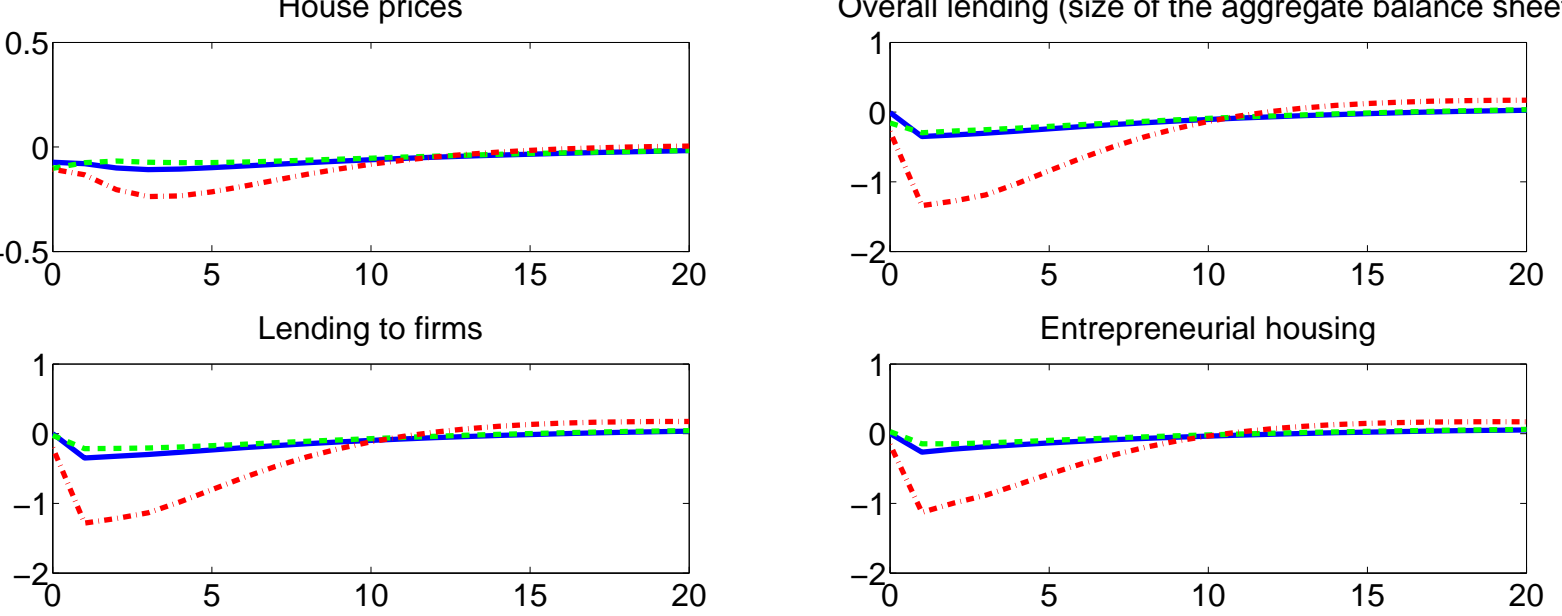

- Benchmark model without securitization
- - - Securitization: savers buy senior MBS tranche
- - Securitization: commercial bankers buy senior MBS tranche

Figure 8: Impulse responses of model versions with and without subprime securitization

Note: All impulse responses are measured in percentage deviations from steady state

\begin{tabular}{cccc}
\hline & \multicolumn{3}{c}{ Standard deviation } \\
Variable & Benchmark & Sec1 & Sec2 \\
\hline Output & 1 & 0.62 & 1.44 \\
Aggregate lending & 1 & 0.7 & 2.09 \\
Nominal interest rate & 1 & 0.72 & 1.31 \\
House prices & 1 & 0.94 & 1.81 \\
Entrepreneurial borrowing & 1 & 0.69 & 2.06 \\
Entrepreneurial housing stock & 1 & 0.62 & 1.75 \\
\hline
\end{tabular}

Table 2: Simulated moments of chosen variables

main variables of interest for the benchmark model and the two versions of the model with securitization. For the purpose of the table, I denote the model with securitization in which entrepreneurs and savers buy MBS as Sec1, and the model in which entrepreneurs and commercial bankers buy MBS as Sec2. I normalize the standard deviations of the benchmark model to 1 and present the standard deviations for the other models in relation to the benchmark, so the numbers presented in columns 2-4 have a percentage interpretation. A number smaller than 1 means that a given variable is less volatile relative to the benchmark model without securitization, while a number larger than 1 denotes larger volatility.

In case of each variable, the standard deviation of the model in which commercial bankers buy the senior MBS tranche ( $\operatorname{Sec} 2)$ is considerably larger than in the benchmark case without securitization. In the case of the model where entrepreneurs and patient households (Sec1) buy MBS tranches, the opposite is the case: the model exhibits a much smaller volatility of 
U.S. real GDP growth, percent deviations from trend

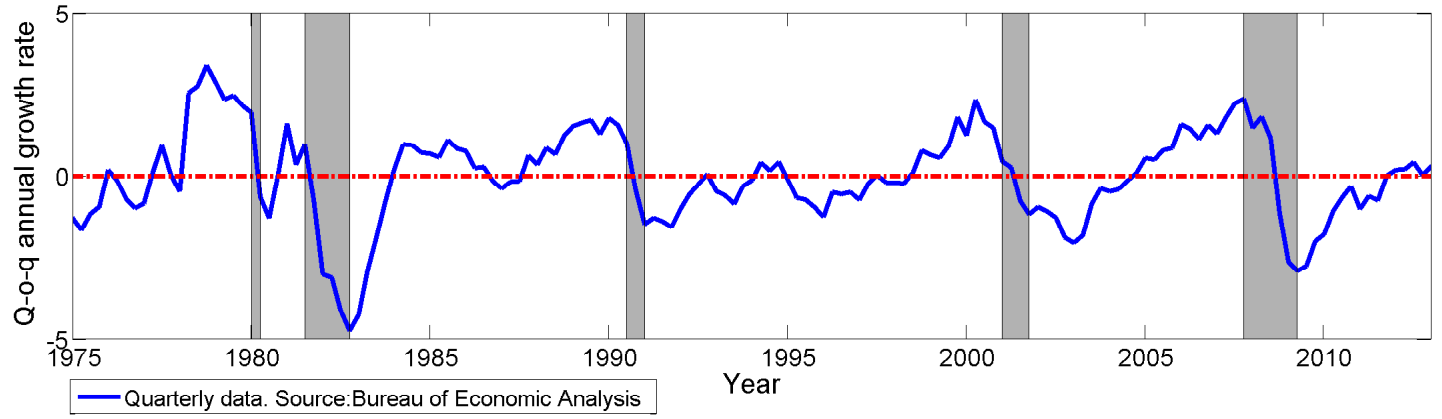

U.S. house price index, percent deviations from trend

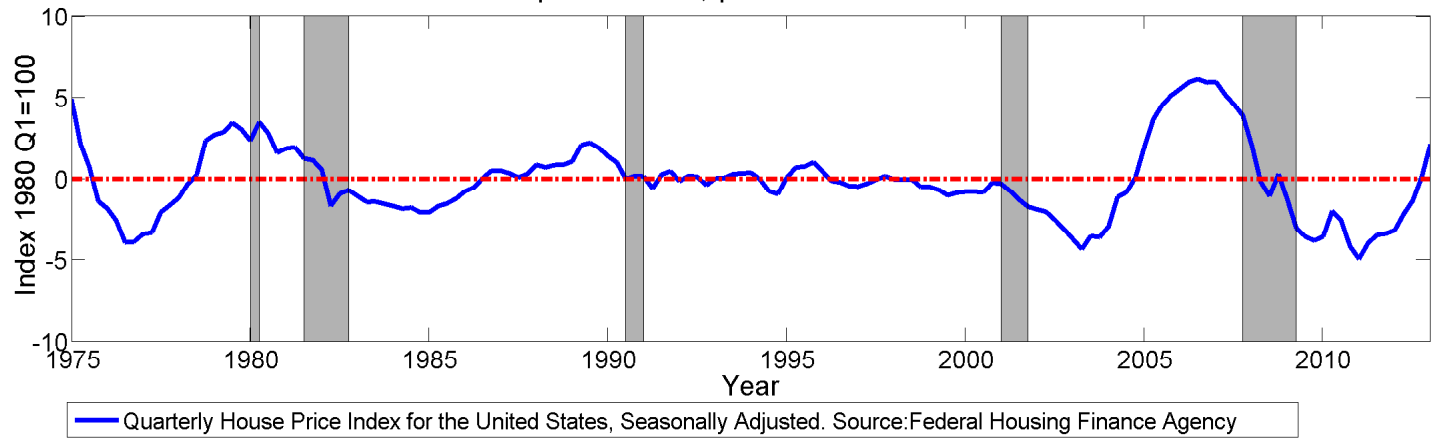

Figure 9: U.S. GDP and USSTHPI

considered variations relative to the benchmark. Thus, the simulated moments of the economy confirm the intuition provided by the analysis of impulse response functions: securitization may either dampen or amplify aggregate volatility depending on the final buyer of securitized assets.

\subsection{Crisis Experiment}

How do the model's predictions relate to the housing prices and output fall observed in the data during the Great Recession? To answer this question, I take into account the seasonally adjusted USSTHPI series ${ }^{26}$ and real GDP (available from the Bureau of Economic Analysis). The raw data exhibits a trend in both cases. In order to make the data comparable to the model outcomes presented as percentage change from the steady state, I use the HP-filter to calculate the trend and cyclical component of both series and express the cyclical component as percentage deviations from the trend. Figure 9 presents the percent deviations from trend observed in the data for real GDP (upper panel) and housing prices (lower panel) in the U.S. in the years 1975-2013. The gray bars indicate NBER recessions. The last recession started in December 2007 (4th quarter) and ended in June 2009 (2nd quarter).

The analysis reveals that the cyclical component of housing prices fell below zero (steady

26 The series has been adjusted using the X-12-ARIMA program. 
state) between the 4th quarter of 2007 and the 1st quarter of 2008 (and crosses the zero-line from below for one period in the 2nd quarter of 2008), while the cyclical component of GDP turned negative two quarters after housing prices fell, in the 3rd quarter of 2008. Notice that the time when the cyclical component turns negative does not coincide with the peak of GDP and housing prices, as in both cases, the peaks represent positive cyclical divergence from the steady state. Using a log-linearized DSGE model as an analysis tool, I can by construction only look at the deviations from the steady state - before the exogenous shock occurs, the economy is at the steady state. After the cyclical component of house prices turns negative, it reaches a first low of $-3.81 \%$ in the 4th quarter of 2009 and the second low of $-4.91 \%$ in the 1 st quarter of 2011. The low of the GDP cyclical component, $-2.91 \%$, occurs earlier, even if the fall itself starts later, and experiences a relatively fast recovery afterwards (while the cyclical component of housing prices shows a W-shaped pattern).

To investigate how the predictions of my stylized model correspond to the dynamics observed in the data, I calibrate the housing preference shock in the model with securitization, in which commercial bankers buy the senior MBS tranche (since this model is most likely to correspond to the scenario that was in place during the crisis), to get an initial fall in housing prices of $2.2518 \%$, as this has been the cumulated two-quarter fall in the cyclical component of housing prices when it first turned negative (house prices went from $2.0601 \%$ above the trend to $0.1917 \%$ ). Subsequently, I apply the same-size shock to two other models that I consider in the paper. Importantly, the standard deviation of the preference shock is the only parameter that I change in the original model calibration, all other parameters have the values presented in Table 1. Figure 10 shows the results of this exercise, presenting the impulse response functions for three models and the data series (starting from the 3rd quarter of 2008, when the cyclical component of GDP turns negative and the cyclical component of housing prices falls below zero for the second time) for the first 10 quarters after the shock.

The model, especially its version with banks investing in MBS, does a good job replicating the hump-shaped response of output and housing prices after the negative preference shock. While the model most credibly depicting the crisis scenario (red dashed-dotted line) generates a maximum fall in housing prices of $4.55 \%$ (compared to $4.91 \%$ in the data in the 9 th quarter), the model without securitization (solid blue line) generates a maximum fall in housing prices of $2.42 \%$ and the model with securitization, in which only non-financial agents of the economy buy MBS tranches (dashed green line) generates a maximum fall in housing prices of $2.2782 \%$. When it comes to the output, the crisis-scenario model prediction (red dashed-dotted line) almost coincides with what was observed in the data (light blue dotted line with round markers). The cyclical component of output went down by $2.91 \%$ (in the second quarter on the Figure 10), while the crisis-scenario model prediction is $-2.85 \%$. The other model versions, represented by the blue solid line (model with no securitization) and by the dashed green line 


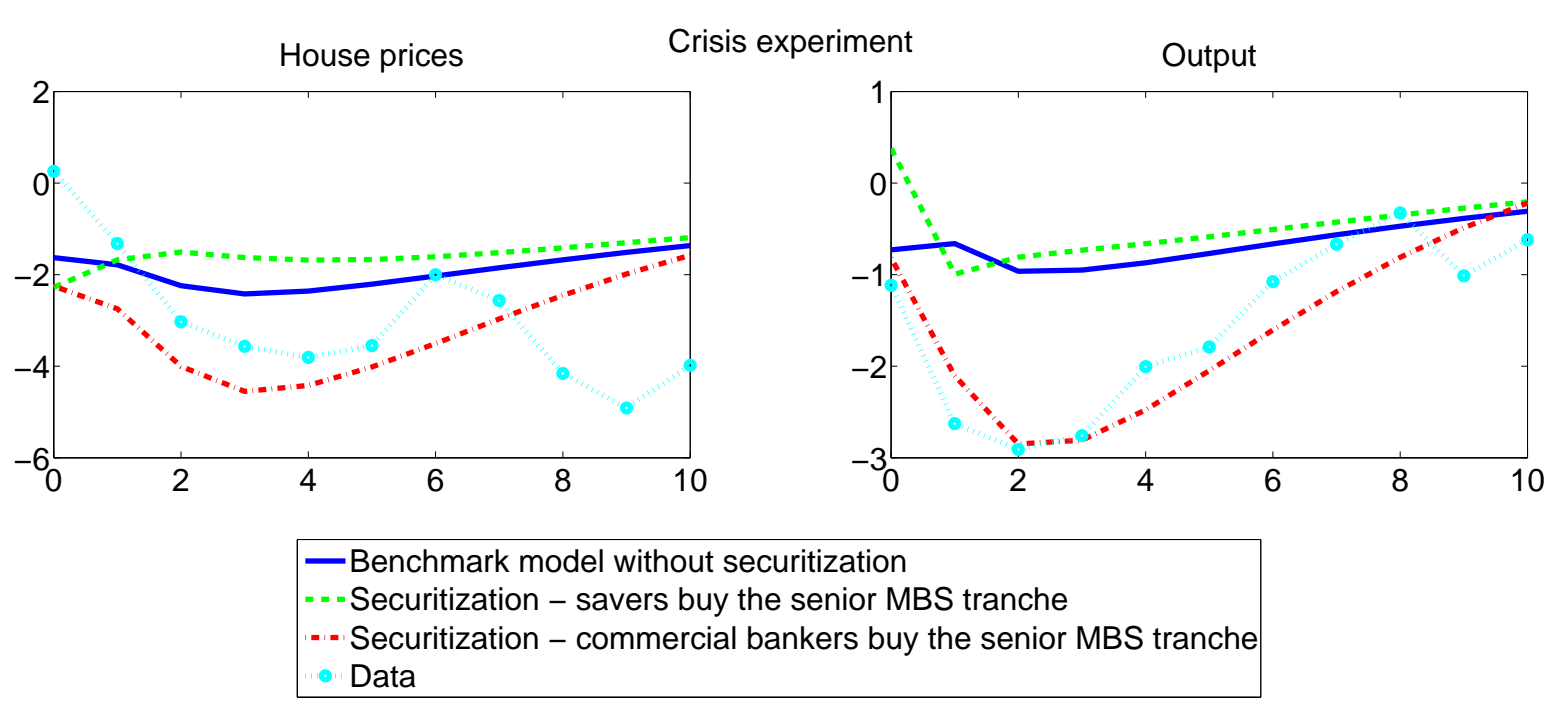

Figure 10: Crisis experiment

Note: All impulse responses are measured in percentage deviations from steady state

(model with securitization, in which only non-financial agents buy MBS), can be treated as crisis counterfactuals and suggest that if only MBS did not end on the balance sheets of commercial banks, instead of a $2.9 \%$ maximum fall in output, we would see only a decline of ca. $1 \%$, hence, around $65 \%$ lower.

Despite the simplicity of the model, the counterfactual calculations are likely to give a credible picture of what could have happened in the US economy, if not for the fact that financial intermediaries were putting skin in the securitization game of the others. The crisis scenario assumes that senior tranches of the MBS were bought exclusively by commercial banks, which may amplify the effects of simulations, but, at the same time, I assume that the sizes of tranches were fixed in the case of subprime securitization, while, as Gorton (2008) describes, they were not. Fixed tranche sizes, in turn, have a dampening effect on the simulations. Given the existence of Rule 144A and indirect exposures of banks to subprime losses, it would be difficult to pin down one number determining banks' exposure to subprime risk. Moreover, in the present calibration of the model I assume that all borrowing households are subprime, which is likely to amplify the effects of subprime securitization. However, my calibration of the sensitivity of subprime borrowers' defaults to changes in housing prices corresponds to that parameter from 2004 in the data. During the crisis, the default sensitivity of subprime households was much larger than my benchmark calibration (even fourfold, see Amromin and Paulson, 2010). As such, this conservative calibration is a counterweight to the assumption about the proportion of subprime borrowers in the economy. 
Difference between model without securitization and with (banks investing), monetary shock House prices

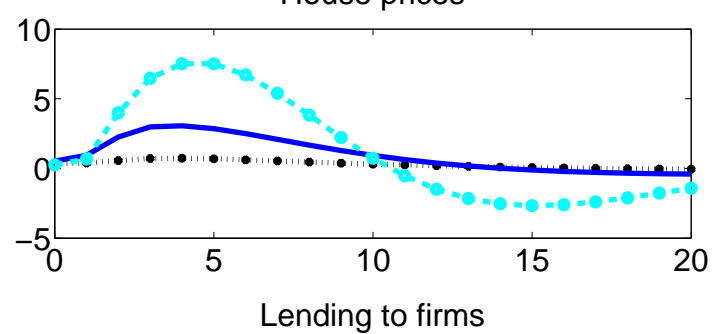
Output

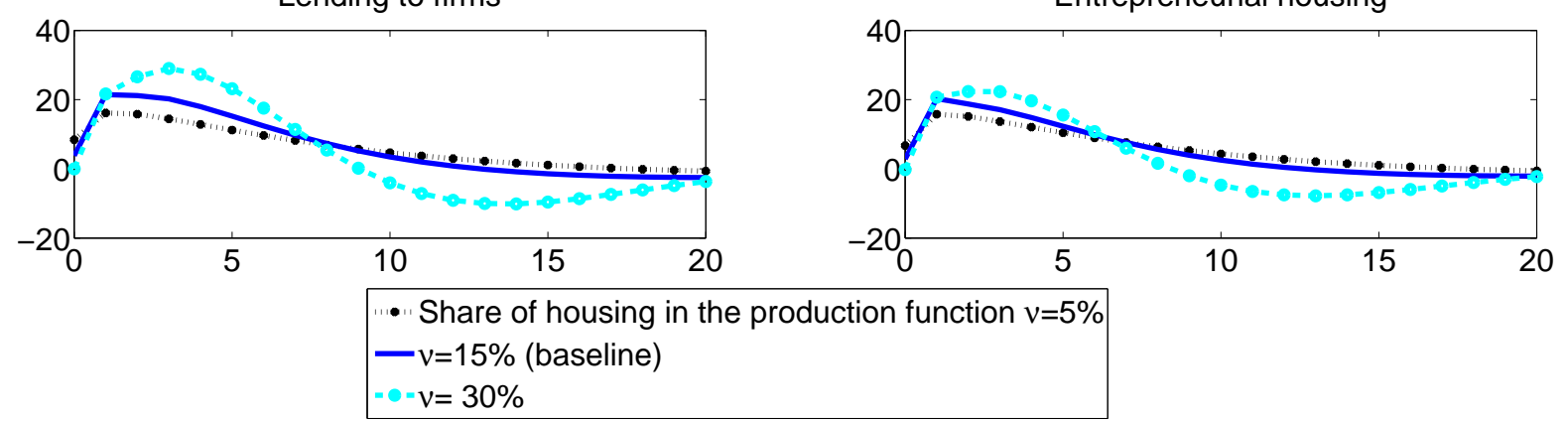

Figure 11: Sensitivity w.r.t. $\nu$

\section{Sensitivity Analysis}

\subsection{Sensitivity Analysis}

In order to test the model's robustness, I conduct sensitivity analysis with respect to the housing share in the production function, commercial bankers' capital ratio and tranche retention by subprime lenders. The results are presented as the difference between the IRFs of the benchmark model (solid blue line in all graphs) and the model with securitization in which bankers are the investors, after a monetary shock. ${ }^{27}$ The larger the difference, the larger the negative effect compared to the economy without securitization.

Figure 11 presents the differences for different values of housing share in the production function. The larger the housing share, the stronger the negative effects of securitization on housing prices and output. This is an intuitive result: given that entrepreneurial housing stock falls in response to the negative shock, if it is a relatively more important factor of production ( $\nu$ is larger), output will experience a larger drop.

From the policymaker's point of view, it is important to examine the effects of increasing regulation in the banking market. Could more strict regulations, i.e. higher capital ratios and higher tranche retention rates protect the economy from large output falls, analogous to those that occurred during the Great Recession? Figure 12 presents the sensitivity analysis w.r.t. different capital ratios, and Figure 13 presents results for different tranche retention rates.

Figure 12 shows that, as capital ratios for commercial bankers increase, the difference be-

${ }^{27}$ Results for the preference shock are qualitatively the same. 
Difference between model without securitization and with (banks investing), monetary shock House prices

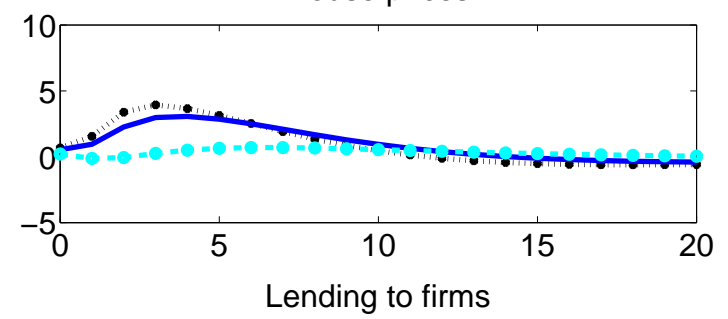

Output

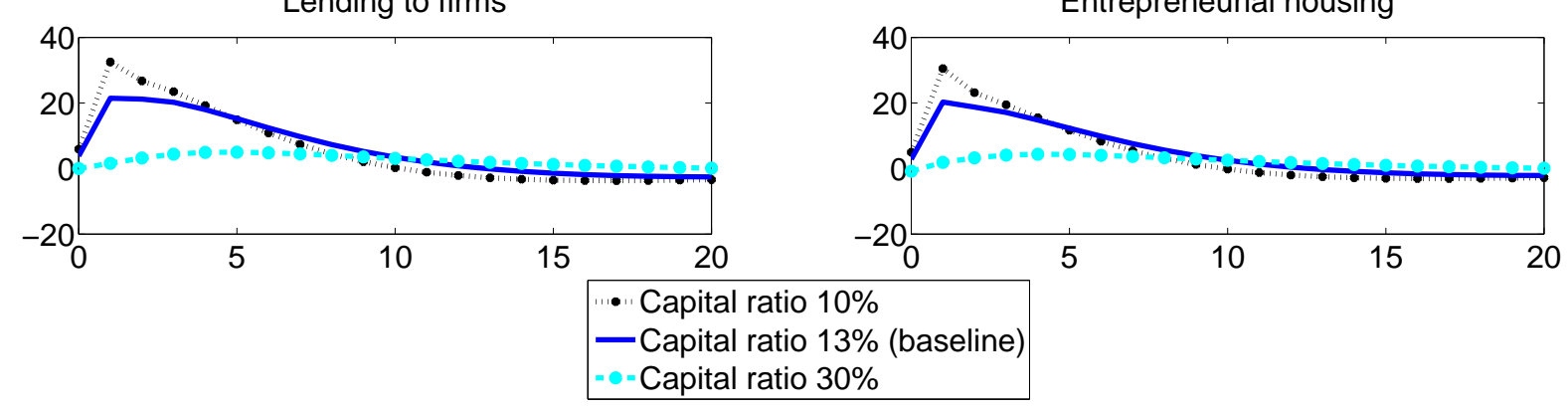

Figure 12: Sensitivity w.r.t. $\tau$

tween the baseline model and the model with bankers as investors in securitized assets falls. This suggests that, given the existence of equity constraints, their higher value is better for the economy, as it reduces deleveraging effects and the fall in housing prices and output. When it comes to imposing higher retention rates on subprime lenders, Figure 13 suggests that such a macroprudential policy is less effective than determining the level of capital ratios. Higher retention rates lead to smaller differences between the baseline and the 'bad securitization' model, but the effects are quantitatively negligible even for tranche retention rates as high as $50 \%$. This can hinge on the fact that the subprime lending sector is more regulated in the first place. Higher capital ratios for subprime lenders and high risk weights on subprime loans significantly reduce the leverage of the subprime sector as compared to the commercial banking sector, so introducing stricter regulations has a relatively smaller marginal impact on the behavior of the economy. 
Difference between model without securitization and with (banks investing), monetary shock House prices

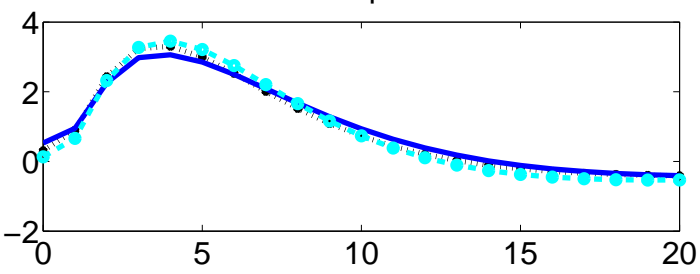
Output

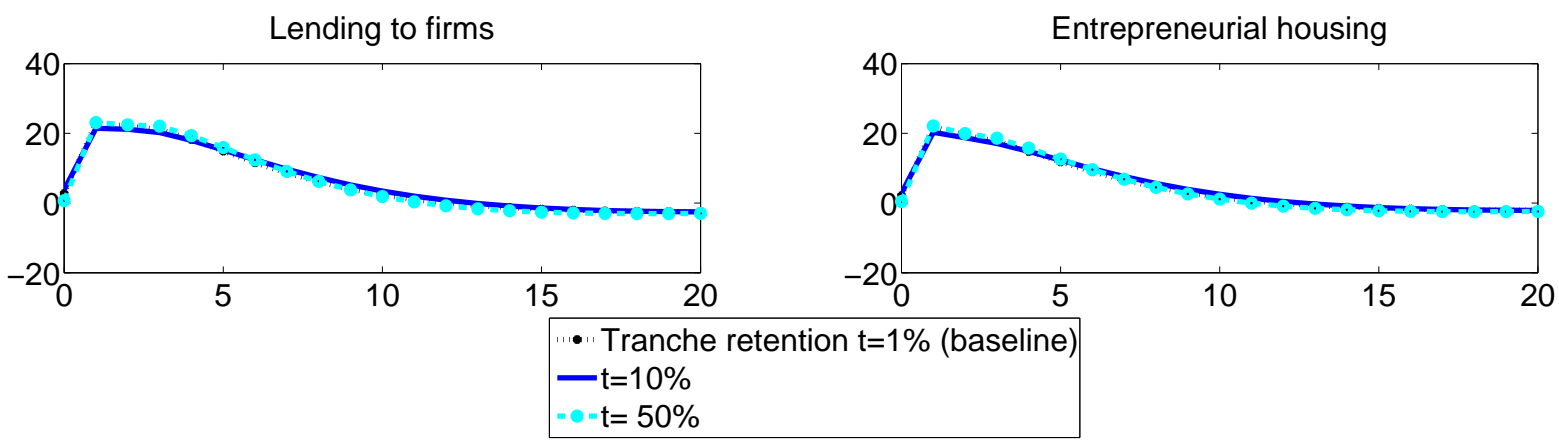

Figure 13: Sensitivity w.r.t. $t$

\section{Conclusion}

In this paper, I analyze the importance of the specific design of subprime contracts and the securitization of subprime loans in generating cyclical fluctuations in the U.S. in a NewKeynesian model and I quantify their importance for the output drop in the U.S. during the Great Recession. It turns out that the effects of securitization of subprime loans depend on who is the final buyer of securitized assets. If households and entrepreneurs purchase MBS tranches, securitization reduces business cycle fluctuations, spreading the subprime risk among different agents. Facing a negative shock and losses on securitized portfolios, these agents adjust their labor supply and saving decisions (patient households) or borrowing (entrepreneur) so as to cushion the effects of the exogenous disturbances. The positive effects of securitization arise thanks to an interconnected banking sector in which changes in the balance sheet of one financial intermediary have an impact on the balance sheets of other financial intermediaries in the economy through interbank loan contracts. However, if financial intermediaries (that are the source of credit to firms in the economy) purchase MBS tranches, the negative effects of securitization prevail. This results in a bigger contraction of output after a negative shock when compared with the case where non-banks buy MBS tranches or without securitization. The positive risk-sharing aspect of securitization is mostly suppressed in this situation, because the capital requirement on the side of banks is a source of additional financial frictions. The financial crisis and its aftermath showed that banks were highly exposed to losses in the subprime mortgage market and as such, the model presented in this paper in which financial 
intermediaries buy MBS can be interpreted as the crisis-scenario.

The counterfactual exercise conducted in this paper suggests that if financial institutions followed the intended business model of securitization, the maximum quarterly output loss in the U.S. economy during the Great Recession would have been much smaller, even only one third, compared to that actually experienced. The results of the model are in line with narrative explanations of the crisis provided by Acharya and Schnabl (2009), Hellwig (2009) and Jaffee et al. (2009). It is shown that securitization per se cannot be blamed for the crisis, because it may dampen business cycles arising in response to negative shocks if the securitized products are bought by agents that do not play the role of a financial intermediary in the economy. Obviously, it may be that unless there was the possibility of securitization, the bankers would not issue as many subprime loans as they did in the first place. The present model deals, however, with the possible transmission mechanism in an economy with subprime borrowers and securitization, rather than the reasons for the existence of the subprime market and the subprime securitization with their incentive problems.

The setup addresses several important issues in policymaking, like the burden of regulation in the economy. It turns out that raising capital ratios is an effective method of reducing negative deleveraging effects, while imposing higher tranche retention rates on subprime lenders is relatively less efficient, as they are already more regulated and the marginal effect of additional regulation is comparatively small. Moreover, the paper's results suggest that the segmentation of the banking sector and avoiding interbank linkages between banks operating in different segments may be a good way of preventing the negative spillovers of credit defaults in the economy. This may not only reflect the separation of the subprime and prime loans segments, but also the separation of commercial and investment banking, which was the case in the United States for several decades due to the Glass-Steagall Act of 1933. The separation between commercial and investment banks was abolished at the beginning of the new century, and it might have been one of the causes of the widespread crisis, as the current paper shows. Thus, from the point of view of the policymaker, it is crucial to ensure that banks disclose all information about their assets, even those hidden from the balance sheet that may give a hint about potential linkages between different banking sectors and branches. Equally, the improvement in the rating process would enable to better couple the risk weights on the banks' balance sheets with underlying risks. However, if we want to insure that securitization improves the risk transfer, than financial intermediaries should not invest in certain types of assets and their derivatives, as this paper suggests.

The model operates in a closed-economy setup, however it is easy to imagine that the two banking sectors presented in the model represent financial intermediaries of two different countries. ${ }^{28}$ If toxic assets generated in country A are sold to commercial banks in country B, coun-

\footnotetext{
${ }^{28}$ Kollmann et al. (2011) investigate the role of bank capital requirements in the international context, modeling a
} 
try A is basically able to transfer all the default risk and losses to country B, which will suffer from a recession due to the engagement in the international financial market (country A will remain practically intact). This narrative can be easily adopted to explain what happened during the recent financial crisis. The U.S. was the country issuing toxic assets and it was selling them to foreign investors, transferring the subprime risk from the country to the international market. This is why, e.g. many European banks, municipalities etc., had problems when the defaults in the U.S. subprime market started, and the crisis spread around the world. In reality, not only did the international buyers of RMBS suffer from losses, but the U.S. economy experienced a recession as well (thus the country A from our example did not remain intact). This is partially due to the fact that U.S. banks also engaged in the acquisition of toxic assets. Also, other factors, such as labor market developments in the U.S. played a role, which are, however, not considered in this model.

To sum up, this paper combines the macroeconomic framework with financial economics, presenting one important channel that may have played a role in the amplification of the recent crisis in the U.S. economy. It provides evidence that financial intermediaries and the constraints they are facing are an important feature of macroeconomic models, and that one has to take into account the heterogeneity in the financial sector. One representative banker is not enough to explain some of the features of complicated financing and investment schemes, like securitization.

\section{References}

Acharya, V. V. And P. Schnabl (2009): “How Banks Played the Leverage Game," Financial Markets, Institutions \& Instruments, 18, 144-145.

Acharya, V. V., P. Schnabl, And G. SuARez (2013): "Securitization without risk transfer," Journal of Financial Economics, 107, 515-536.

ADRIAN, T. AND H. S. SHIN (2010): "Liquidity and leverage," Journal of Financial Intermediation, 19, 418-437.

(2011): "Financial Intermediary Balance Sheet Management," Annual Review of Financial Economics, 3, 289-307.

Amromin, G. And A. PAulson (2010): "Default rates on prime and subprime mortgages: differences \& similarities," Profitwise, 1-10.

global bank subject to loan default shocks. 
Angelini, P. (2000): "Are Banks Risk Averse? Intraday Timing of Operations in the Interbank Market," Journal of Money, Credit and Banking, 32, 54-73.

Demyanyk, Y. And O. V. Hemert (2011): "Understanding the Subprime Mortgage Crisis," Review of Financial Studies, 24, 1848-1880.

Devereux, M. B. AND A. Sutherland (2010): “Country portfolio dynamics," Journal of Economic Dynamics and Control, 34, 1325-1342.

Dhyne, E., L. J. Alvarez, H. L. Bihan, G. Veronese, D. Dias, J. Hoffmann, N. Jonker, P. Lunnemann, F. Rumler, And J. Vilmunen (2006): "Price Changes in the Euro Area and the United States: Some Facts from Individual Consumer Price Data," Journal of Economic Perspectives, 20, 171-192.

FAIA, E. (2011): “Credit Risk Transfers and the Macroeconomy," Kiel Working Papers.

Forlati, C. And L. Lambertini (2011): "Risky Mortgages in a DSGE Model," International Journal of Central Banking, 7, 285-335.

GEITHNER, T. (2011): "Macroeconomic effects of risk retention requirements," mimeo.

Gorton, G. B. (2008): “The Panic of 2007,” Yale School of Management Working Papers.

Gorton, G. B. And N. S. Souleles (2007): "Special Purpose Vehicles and Securitization,” in The Risks of Financial Institutions, National Bureau of Economic Research, Inc, NBER Chapters, 549-602.

GrodecKA, A. (2013): "Subprime borrowers, securitization and the transmission of business cycles," Bonn Econ Discussion Papers.

(2014): "Subprime borrowers, securitization and the transmission of business cycles," Beitraege zur Jahrestagung des Vereins fuer Socialpolitik 2014.

(2015): Essays on Business Cycles, University of Bonn.

GUERRIERI, L. AND M. IACOVIELlo (2015): “OccBin: A toolkit for solving dynamic models with occasionally binding constraints easily," Journal of Monetary Economics, 70, 22-38.

Hellwig, M. (2009): "Systemic Risk in the Financial Sector: An Analysis of the SubprimeMortgage Financial Crisis," De Economist, 157, 129-207.

Hobijn, B. And F. Ravenna (2010): "Loan Securitization and the Monetary Transmission Mechanism," Tech. rep.

Iacoviello, M. (2005): "House Prices, Borrowing Constraints, and Monetary Policy in the Business Cycle," American Economic Review, 95, 739-764. 
(2014): “Financial Business Cycles," forthcoming in Review of Economic Dynamics.

IMF (2009): Global Financial Stability Report: Navigating the Financial Challenges Ahead, IMF eLibrary.

Jaffee, D., A. Lynch, M. Richardson, And S. Van Nieuwerburgh (2009): "Mortgage Origination and Securitization in the Financial Crisis," Financial Markets, Institutions \& Instruments, 18, 141-143.

JAPPELli, T. (1990): "Who Is Credit Constrained in the U.S. Economy?" The Quarterly Journal of Economics, 105, 219-34.

Jones, D. (2000): "Emerging problems with the Basel Capital Accord: Regulatory capital arbitrage and related issues," Journal of Banking and Finance, 24, 35-58.

JovAnovic̀, M. N. (2013): The Economics of European Integration, Edward Elgar Publishing Limited.

Kiyotaki, N. And J. Moore (1997): “Credit Cycles,” Journal of Political Economy, 105, 211-48.

KLIFF, J. AND P. S. MiLls (2007): "Money for Nothing and Checks for Free: Recent Developments in U.S. Subprime Mortgage Markets," IMF Working Papers.

Kollmann, R., Z. Enders, And G. Müller (2011): "Global banking and international business cycles," European Economic Review, 55, 407-426.

KunCL, M. (2014): "Securitization under Asymmetric Information over the Business Cycle," CERGE-EI Working Papers.

Liebowitz, S. (2009): "ARMs, Not Subprimes, Caused the Mortgage Crisis," The Economists' Voice, 6, 1-5.

Moench, E., J. Vickery, And D. Aragon (2010): "Why Is the Market Share of Adjustable-Rate Mortgages So Low?" Current Issues in Economics and Finance, 16, 111.

NishiYAMA, Y. (2007): “Are Banks Risk-Averse?” Eastern Economic Journal, 33, 471-490.

Peterman, W. B. (2012): "Reconciling micro and macro estimates of the Frisch labor supply elasticity," Finance and Economics Discussion Series.

RATTI, R. A. (1980): "Bank Attitude toward Risk, Implicit Rates of Interest, and the Behavior of an Index of Risk Aversion for Commercial Banks," The Quarterly Journal of Economics, 95, 309-31. 
TEMKIn, K., J. E. H. Johnson, And D. LEVY (2002): "Subprime markets, the role of GSEs, and risk-based pricing," U.S. Department of Housing and Urban Development's Office of Policy Development and Research.

\section{A. Empirical evidence on subprime and prime defaults and foreclosures}

Although there is no exact definition of a subprime borrower or market, there are certain features common to all subprime loan contracts. A prime mortgage in the U.S. is usually collateralized and has a fixed interest rate for 30 years. Subprime borrowers often can provide neither collateral, nor income (so called "NINJAs" - No Income, No Job or Assets, see Jovanovic̀, 2013). The down-payment rate in the case of prime borrowers is usually higher than in the subprime case. However, the difference is not as overwhelming as one may expect (see Amromin and Paulson, 2010). The biggest difference between these two groups has been noted in the FICO score, which measures the creditworthiness of borrowers and is used by lenders to determine the credit risk. In the case of prime borrowers it ranged from 706 to 715 , while in the case of subprime borrowers, it ranged from 597 to 617 (the FICO score ranges from 300 to 850 , with the higher, the better). Subprime borrowing was thriving thanks to a common belief that housing prices will rise on average. Indeed, until the recent crisis the U.S. market did not experience a countrywide decrease in housing prices since the 1930s.

The distinguishing feature of subprime mortgages was their hybrid character. However, prime borrowers also take out ARM loans. Examining foreclosures and delinquencies data (exclusive of loans in the foreclosure process) enables me to address the question of whether the subprime market or the ARM market was decisive for the GDP developments. ${ }^{29}$ Figure 14 depicts the share of mortgages entering the foreclosure process in the U.S., both for subprime and prime borrowers, taking into account ARM and FRM (fixed rate mortgages). Figure 14 reveals that the fraction of foreclosures is the highest among ARMs, but it is clear that the fraction of subprime foreclosures was higher and prime foreclosures only followed the developments in the subprime market. Figure 15 presents delinquencies for the same type of loans. Notably, although ARM delinquencies are much higher than FRM delinquencies for both types of borrowers, in the case of subprime borrowers, the FRM delinquencies are almost as high as delinquencies on the hybrid loans, and much higher than any delinquencies observed for prime borrowers. It seems thus that the combination of subprime borrowing and adjustable rate mort-

\footnotetext{
${ }^{29}$ Some commentators (see Liebowitz, 2009) argue that subprime borrowers themselves were not an issue, but rather adjustable rate mortgages (particularly hybrid mortgages) that led to disruptions in both the subprime and prime mortgage markets.
} 


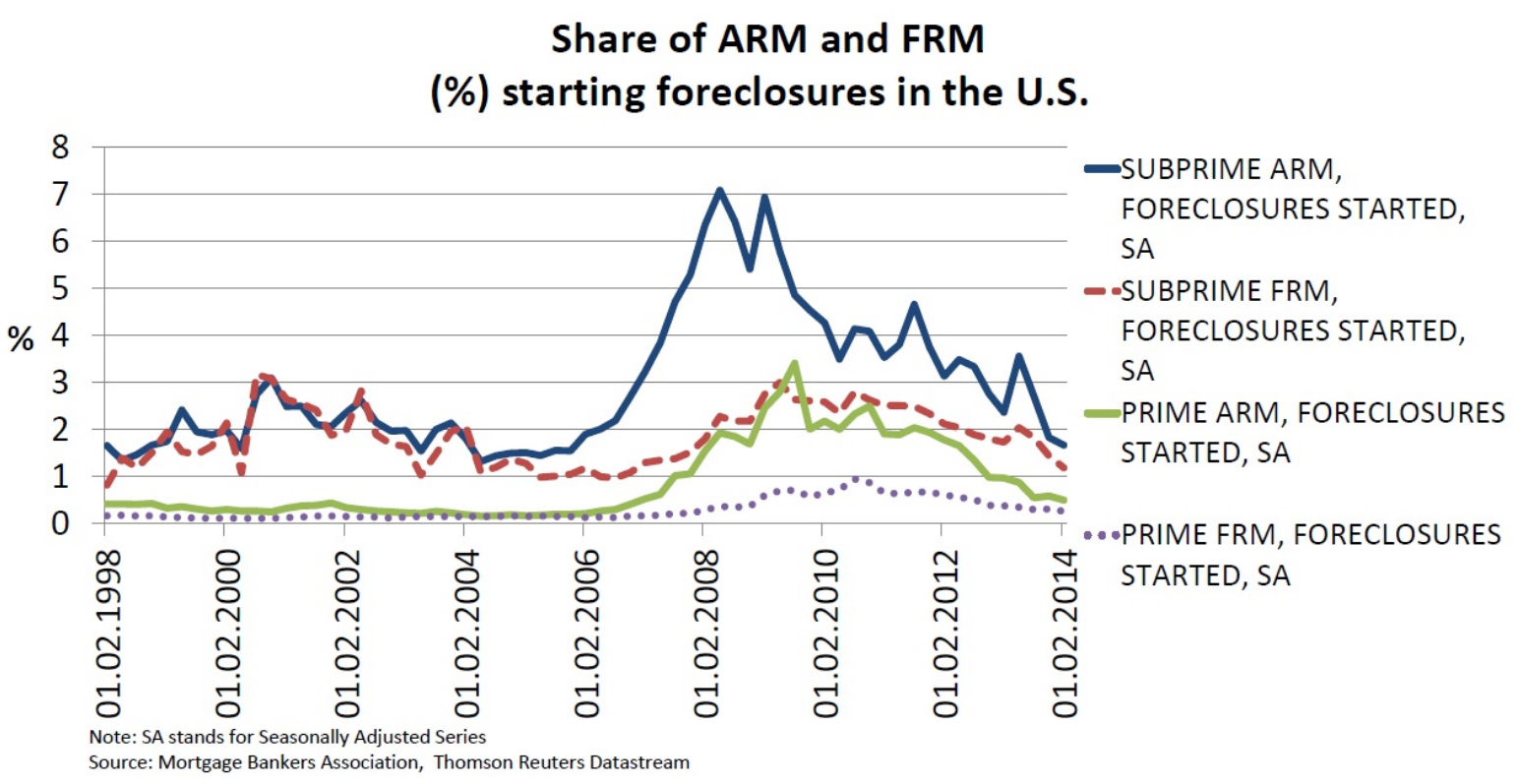

Figure 14: Foreclosures

gages turned out to be critical. The focus of this paper is put on hybrid subprime mortgages, the subcategory of ARMs. Their market almost vanished after the crisis. However, ARMs still exist within and outside the U.S. despite the drop in the share of the market (see Moench et al., 2010).

\section{B. Securitization}

As securitization was the main financing method for subprime originations, the majority of subprime mortgages were pooled together and sold in the financial market as MBS. The bonds or pass-through securities (called so because the monthly loan payments are passed through to the holders of security) were then sold to pension funds, banks, investment funds and personal investors. The securitization of subprime loans might have made the whole financial system vulnerable to housing prices, which is much less the case when financial intermediaries only securitize prime loans, whose value does not depend so much on the condition of the housing market. Moreover, it is important to stress that securitization is not equal to loan sales. A sold loan is no more marketable than the loan itself, whereas securitization creates a new quality through various credit enhancements. ${ }^{30}$ Loans are sold in a secondary market, whereas securitization creates a new primary market. That is why Gorton (2008) calls the chain of securitized subprime securities a chain of many primary markets. At the first stage, securitization is often conducted via a special purpose vehicle (SPV) that exists only for the purpose of securitiza-

\footnotetext{
${ }^{30}$ Credit enhancement includes: tranching of the risk of loss, over-collateralization, guarantee by an insurance company. Discussed further in Gorton and Souleles (2007).
} 


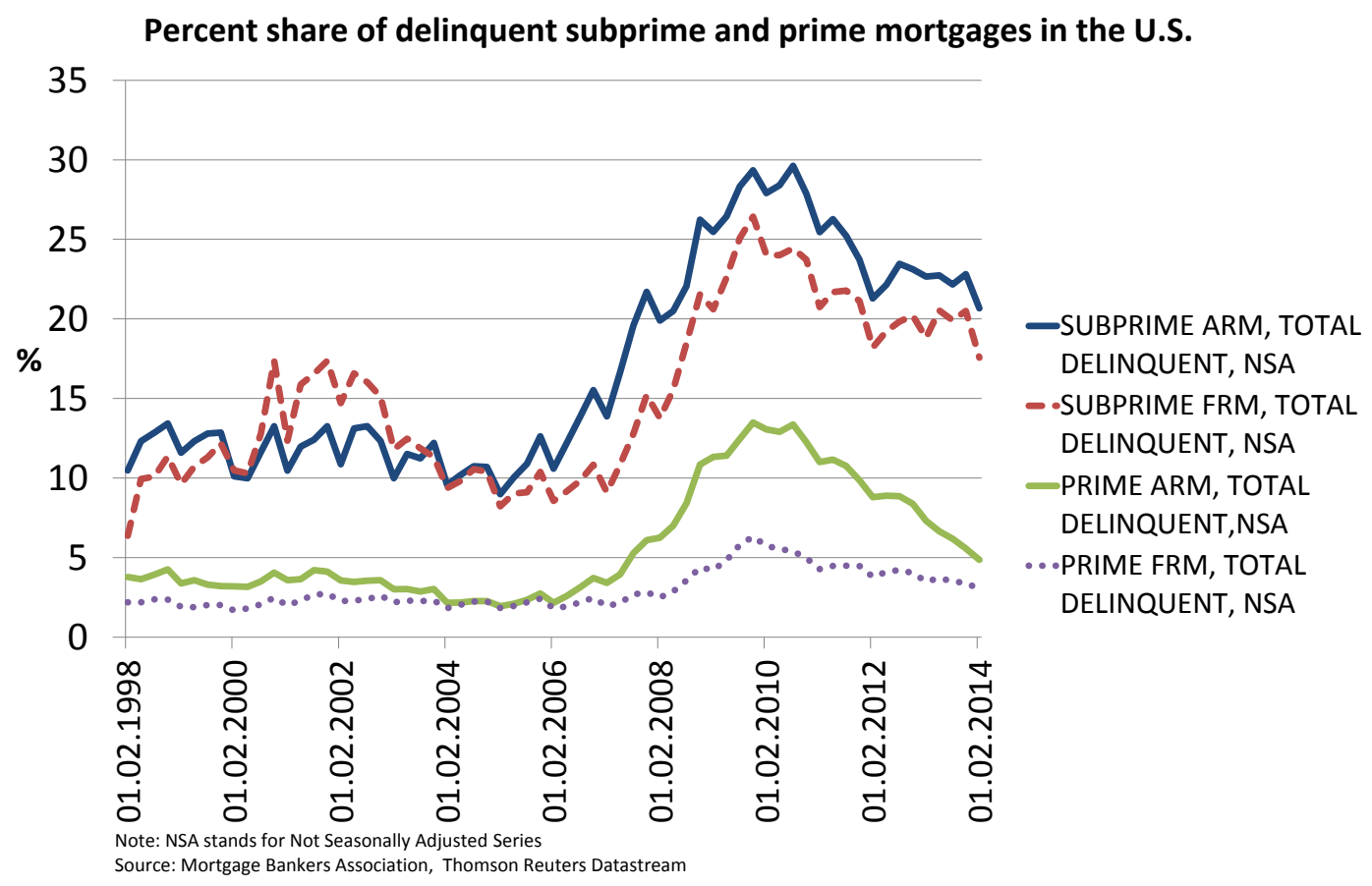

Figure 15: Delinquencies

tion, is set up by the originator, and does not even have any employees. The securitization process includes repackaging many assets, including car or student loans into derivative securities consisting usually of three tranches: senior, mezzanine and equity, with the latter being the most risky one. The process of tranching is the most important credit enhancement of securitized products, without which it would be difficult to explain the demand of investors for the product. Individual pricing and payoff structures of distinct tranches provide incentives for the acquisition - e.g. senior tranches were usually given an A rating by rating agencies, which made them a perfect asset for banks wanting to loosen their capital requirement. The residential mortgage backed securities (RMBS) played the biggest role in the securitization market just before and after the recent financial crisis. Consequently, in my model, I concentrate on RMBS. The specific design of SPVs enables me to model the securitization process without introducing a new agent into the model economy. 


\section{Additional Graphs}

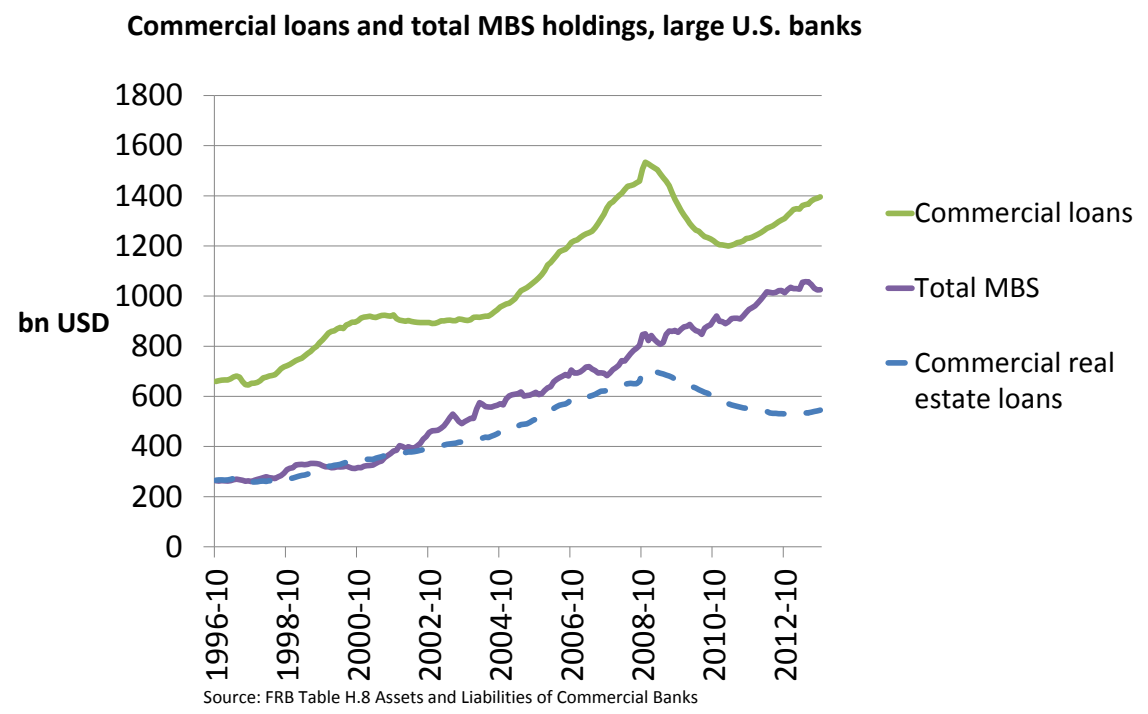

Figure 16: Commercial loan holdings in the U.S., large banks

Figure 17 shows the negative correlation between the fraction of commercial real estate loans on the asset side of the bank and the subprime default rates for the period 2006-2010. Figure 18 presents the correlation for the whole sample period 1998-2013. No visible correlation can be observed in the pre-and post-crisis data.

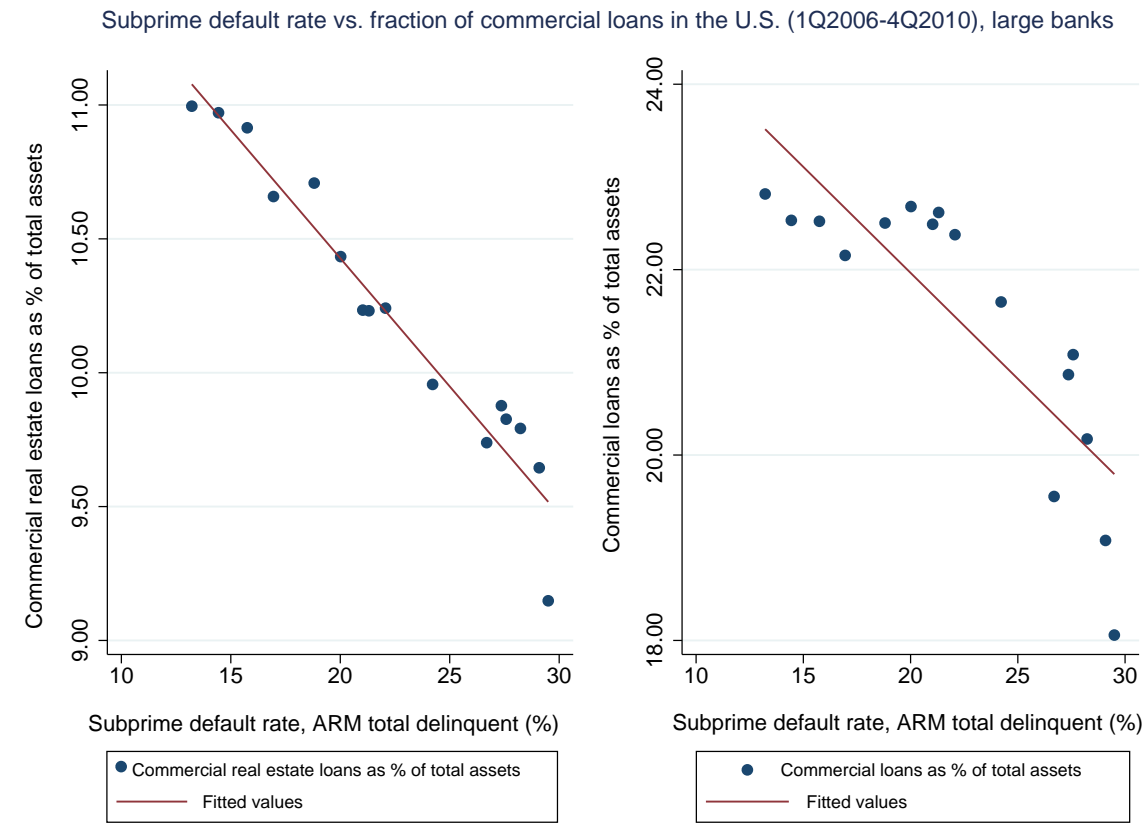

Figure 17: Subprime default rates and commercial loans in the U.S., large banks Source: Thomson Reuters Datastream and FRB data 

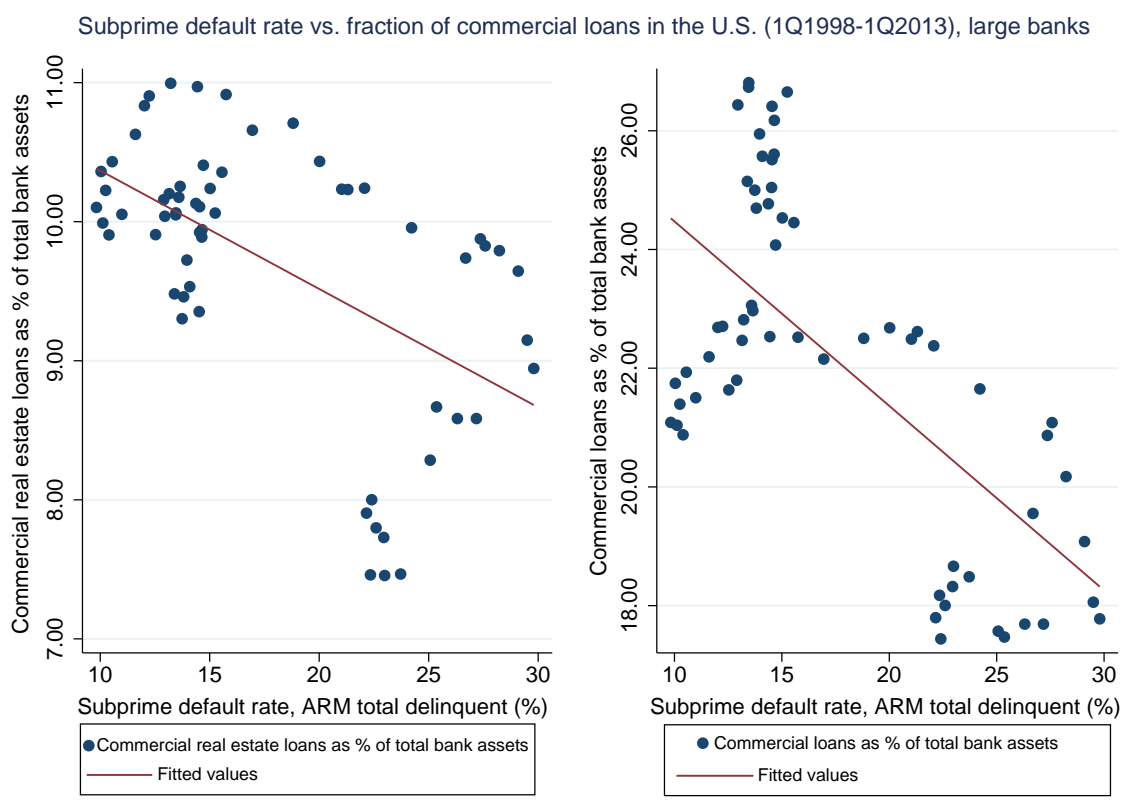

Figure 18: Subprime default rates and commercial loans in the U.S.

Source: Thomson Reuters Datastream and FRB data

If one takes the agency and non-agency MBS held by banks separately into account, it turns out that the agency MBS holdings were going up, while the non-agency MBS holdings stabilized at the peak of the crisis (which confirms the illiquidity hypothesis) and started to experience a persistent decline at the end of 2009, which is depicted in Figure 19 . The Figure 20 shows the agency and non-agency MBS holdings as a fraction of total assets.

\section{Data Description}

To produce the Figures 17 and 18 and compare them to the data for all U.S. chartered banks, I use monthly data provided by the Federal Reseve in Table H.8 Assets and Liabilities of Commercial Banks in the United States. ${ }^{31}$ The data on MBS holdings and data on commercial real estate loans begins in 10.1996 for large commercial banks. If I wanted to use data for all commercial banks, the data on MBS holdings starts in 07.2009 and the data on commercial real estate loans begins in 06.2004. Since I am interested in a longer perspective, I use data for large banks as a proxy for all U.S. banks. The total assets of the large domestically-chartered commercial banks constituted in years 1985-2013 around 56\% to $68.5 \%$, with a falling tendency over time. The developments in the fractions of total commercial loans and commercial real estate loans follow similar patterns. In the period 06.2004-06.2013, the correlation coefficient

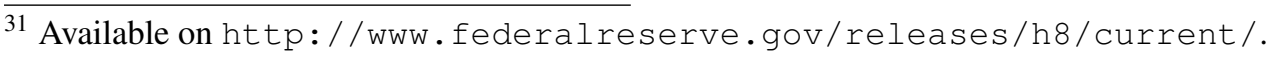




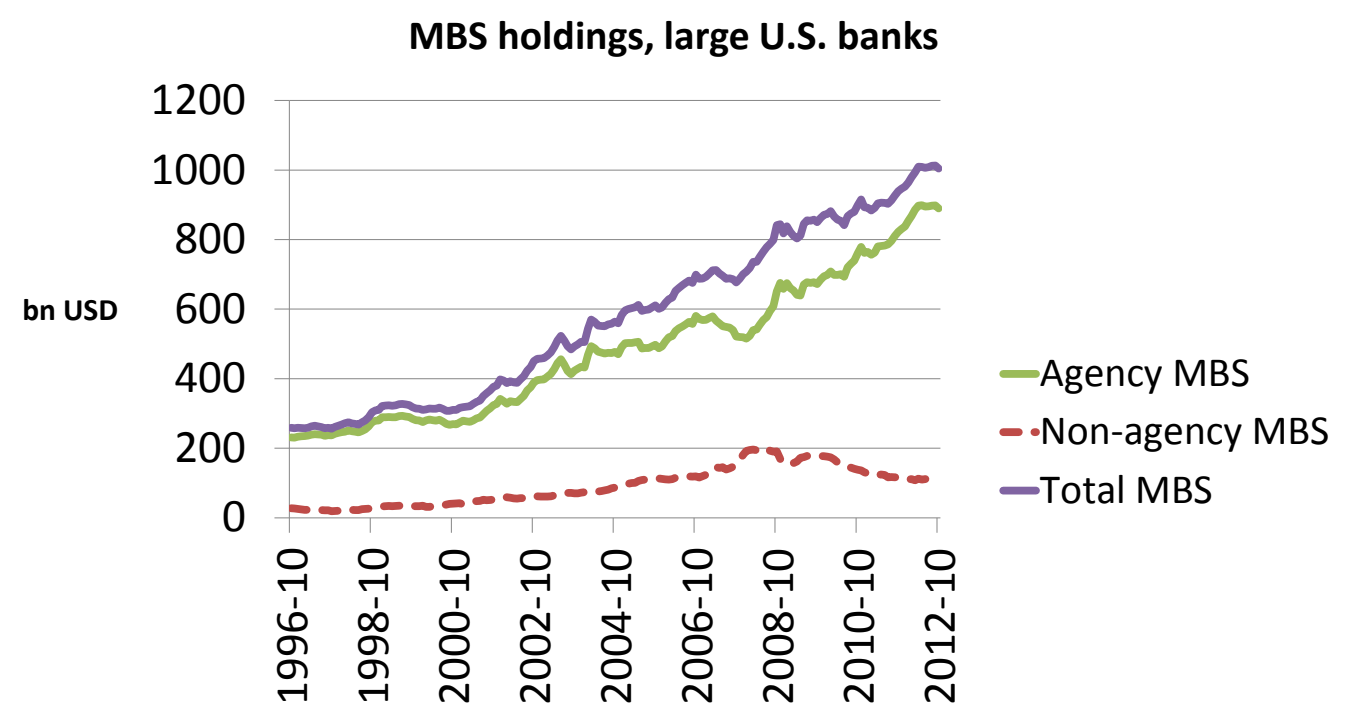

Source: FRB Table H.8 Assets and Liabilities of Commercial Banks

Figure 19: MBS holdings, large U.S. banks

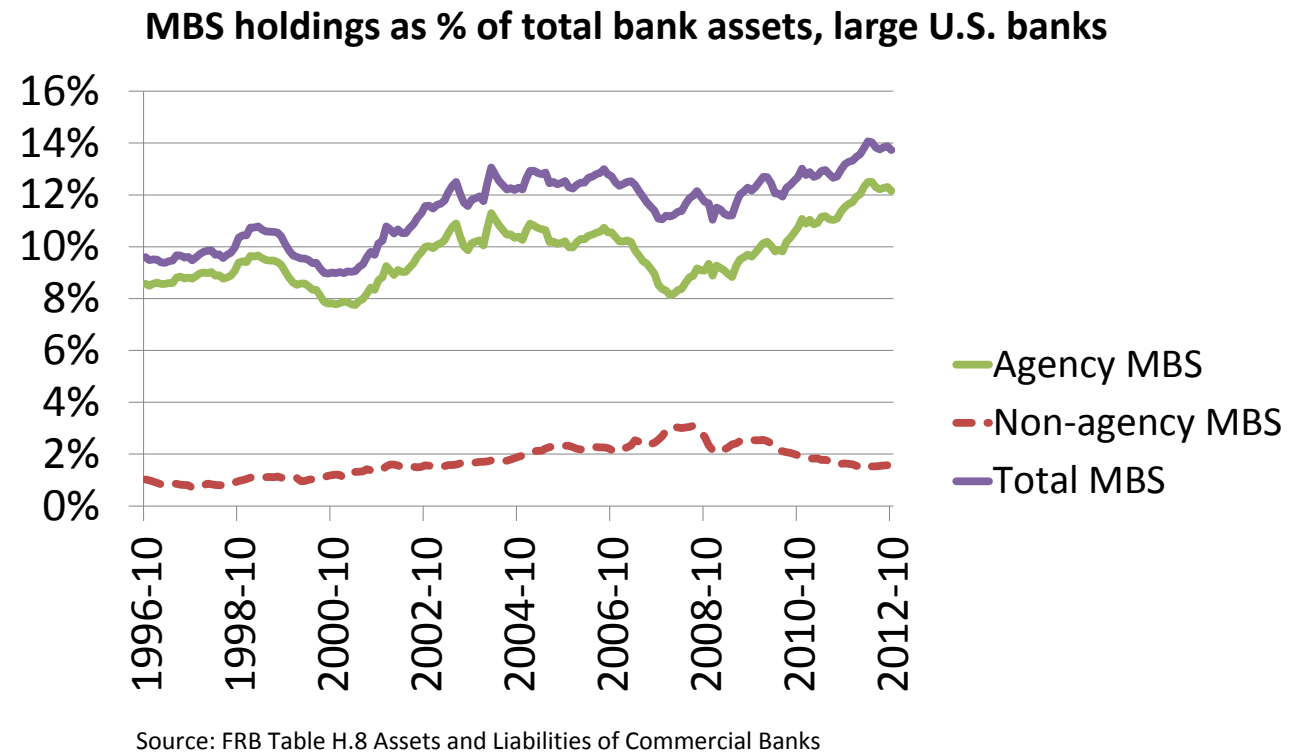

Figure 20: MBS holdings as fraction of total bank assets, large U.S. banks 
between the fraction of total commercial loans in large domestically-chartered banks and all banks stood at $91.14 \%$. For the fraction of commercial real estate loans, the coefficient in the same period was even larger: $95.38 \%$. Thus, the conclusions remain relevant for the whole banking sector in the U.S., even though some of the graphs in this paper are only prepared using data for large domestically-chartered banks. For total consumer loans, the corresponding correlation coefficients are significantly lower: for the fraction of consumer real estate loans we obtain a correlation of $61.34 \%$, while for the fraction of total consumer loans the correlation is $59.02 \%$.

I use the following series:

\section{For large domestically chartered commercial banks:}

Commercial and industrial loans: B1023NLGAM

Commercial real estate loans:B1219NLGAM

Commercial loans: B1023NLGAM + B1219NLGAM

Treasury and agency securities: Mortgage-backed securities (MBS): B1301NLGAM

Other securities: Mortgage-backed securities: B1303NLGAM

Total MBS holdings: B1301NLGAM+ B1303NLGAM

Consumer real estate loans: B1027NLGAM + B1220NLGAM

Other consumer loans: B1029NLGAM

Total consumer loans: B1029NLGAM+ B1027NLGAM + B1220NLGAM

Total assets:B1151NLGAM

\section{For all commercial banks:}

Commercial and industrial loans: B1023NCBAM

Commercial real estate loans: B1219NCBAM

Commercial loans: B1023NCBAM+ B1219NCBAM

Treasury and agency securities: Mortgage-backed securities (MBS): B1301NCBAM

Other securities: Mortgage-backed securities: B1303NCBAM

Total MBS holdings: B1301NCBAM+ B1303NCBAM

Consumer real estate loans: B1027NCBAM+B1220NCBAM

Other consumer loans: B1029NCBAM

Total consumer loans: B1029NCBAM+ B1027NCBAM+B1220NCBAM

Total assets: B1151NCBAM 


\section{E. Benchmark Model Equations}

\section{E.1. The Optimization Problem of the Patient Household}

All equations and constraints are written in real terms. Patient households maximize the utility function given by:

$$
\max _{b_{t}^{\text {Savers }}, h_{t}^{\text {Savers }}, L_{t}^{\text {Savers }}} E_{0} \sum_{t=0}^{\infty} \beta^{t}\left(\log c_{t}^{\text {Savers }}+j_{t} \log h_{t}^{\text {Savers }}-\frac{L_{t}^{\text {Savers } \eta^{\text {Savers }}}}{\eta^{\text {Savers }}}\right),
$$

where $c_{t}^{\text {Savers }}$ denotes the consumption of the final good, $j_{t}$ is the marginal utility of housing subject to random disturbances (following Iacoviello, the disturbance is common to patient and impatient households, and is a proxy for a housing demand or housing preference shock), $h_{t}^{\text {Savers }}$ is the housing stock held by savers, $L_{t}^{\text {Savers }}$ denotes labor supply of patient households.

The budget constraint of the patient household in real terms is:

$$
c_{t}^{\text {Savers }}+q_{t}\left(h_{t}^{\text {Savers }}-h_{t-1}^{\text {Savers }}\right)+d_{t}=R_{d, t-1} d_{t-1} / \pi_{t}+w_{t}^{\text {Savers }} L_{t}^{\text {Savers }}+F_{t},
$$

where $d_{t}$ denotes deposits, $R_{d, t}$ is the interest rate paid on deposits, $F_{t}$ are profits from retailers (redistributed only to patient households), $w_{t}^{\text {Savers }} L_{t}^{\text {Savers }}$ is labor income, $q_{t}=Q_{t} / P_{t}$ denotes the real housing price, $\pi_{t}=P_{t} / P_{t-1}$ is inflation. The deposit contract is a nominal debt contract.

The First Order Conditions (FOCs) are: w.r.t. $d_{t}$

$$
\frac{1}{c_{t}^{\text {Savers }}}=\beta E_{t}\left(\frac{1}{c_{t+1}^{\text {Savers }} \pi_{t+1}}\right) R_{d, t}
$$

w.r.t. $h_{t}^{\text {Savers }}$

$$
\frac{q_{t}}{c_{t}^{\text {Savers }}}=\beta E_{t}\left(\frac{q_{t+1}}{c_{t+1}^{\text {Savers }}}\right)+\frac{j_{t}}{h_{t}^{\text {Savers }}}
$$

w.r.t. $L_{t}^{\text {Savers }}$

$$
w_{t}^{\text {Savers }}=L_{t}^{\text {Savers } \eta^{\text {Savers }}-1} c_{t}^{\text {Savers }}
$$

\section{E.2. FOCs of the Impatient Subprime Household}

The FOCs are ( $\lambda_{t}^{S u b}$ is the Lagrangian multiplier on the borrowing constraint): w.r.t. $b_{t}^{S u b}$ 


$$
\frac{1}{c_{t}^{S u b}}=\beta^{S u b} E_{t}\left(\frac{\left(1-\delta_{s, t}\right) R_{s, t}}{c_{t+1}^{S u b} \pi_{t+1}}\right)+\lambda_{t}^{S u b} R_{s, t}
$$

w.r.t. $h_{t}^{S u b}$

$$
\frac{q_{t}}{c_{t}^{S u b}}=\beta^{S u b} E_{t}\left(\frac{q_{t+1}}{c_{t+1}^{S u b}}+\lambda_{t}^{S u b} m^{S u b} q_{t+1} \pi_{t+1}\right)+\frac{j_{t}}{h_{t}^{S u b}},
$$

w.r.t. $L_{t}^{S u b}$

$$
w_{t}^{S u b}=L_{t}^{S u b \eta^{S u b}-1} c_{t}^{S u b},
$$

\section{E.3. The Optimization Problem and the FOCs of the Entrepreneur}

The utility function of the entrepreneur is:

$$
\max _{b_{e, t}, h_{e, t}, L_{t}^{\text {Savers }}, L_{t}^{\text {Sub }}} E_{0} \sum_{t=0}^{\infty} \gamma^{t} \log \left(c_{e, t}\right),
$$

where $b_{e, t}$ is the borrowing of firms, $h_{e, t}$ denotes their housing stock, $L_{t}$ is the labor of households, and $c_{e, t}$ denotes firms' consumption.

The production function is:

$$
Y_{t}=h_{e, t-1}^{\nu} L_{t}^{\text {Savers }}{ }^{\alpha(1-\nu)} L_{t}^{\text {Sub }}{ }^{(1-\alpha)(1-\nu)}
$$

where $\nu$ denotes the housing share in the production function and the parameter $\alpha$ controls for patient households' labor share in the production function.

The entrepreneurs' budget constraint is:

$$
\frac{Y_{t}}{X_{t}}+b_{e, t}=c_{e, t}+q_{t}\left(h_{e, t}-h_{e, t-1}\right)+\frac{R_{e, t-1}}{\pi_{t}} b_{e, t-1}+w_{t}^{\text {Savers }} L_{t}^{\text {Savers }}+w_{t}^{\text {Sub }} L_{t}^{\text {Sub }}
$$

where $R_{e, t-1}$ is the nominal interest rate on loans between period t-1 and t, and $X_{t}$ is the markup of final over intermediate goods.

Entrepreneurs face a borrowing constraint:

$$
R_{e, t} b_{e, t} \leq m E_{t}\left(q_{t+1} h_{e, t} \pi_{t+1}\right) .
$$

The FOCs of the entrepreneur are (denote by $\lambda_{e, t}$ the Lagrangian multiplier on the borrowing constraint):

w.r.t $b_{e, t}$

$$
\frac{1}{c_{e, t}}=\gamma E_{t}\left(\frac{R_{e, t}}{c_{e, t+1} \pi_{t+1}}\right)+\lambda_{e, t} R_{e, t},
$$


w.r.t. $h_{e, t}$

$$
\frac{q_{t}}{c_{e, t}}=E_{t}\left[\frac{\gamma}{c_{e, t+1}}\left(\nu \frac{Y_{t+1}}{X_{t+1} h_{e, t}}+q_{t+1}\right)+\lambda_{e, t} m q_{t+1} \pi_{t+1}\right]
$$

w.r.t. labor:

$$
\begin{gathered}
w_{t}^{\text {Savers }}=\frac{\alpha(1-\mu-\nu) Y_{t}}{X_{t} L_{t}^{\text {Savers }}}, \\
w_{t}^{\text {Sub }}=\frac{(1-\alpha)(1-\mu-\nu) s Y_{t}}{X_{t} L_{t}^{\text {Sub }}} .
\end{gathered}
$$

\section{E.4. Retailers}

Retailers acquire intermediate goods produced by the entrepreneurs at price $P_{t}^{w}$, then differentiate them into $Y_{t}(z)$ (retailers of mass 1 are indexed by z) and sell at price $P_{t}(z)$. The aggregate output index is given by:

$$
Y_{t}^{f}=\left(\int_{0}^{1} Y_{t}(z)^{\frac{\varepsilon-1}{\varepsilon}} \mathrm{d} z\right)^{\frac{\varepsilon}{\varepsilon-1}}
$$

where $\varepsilon>1$. The price index is given by:

$$
P_{t}=\left(\int_{0}^{1} P_{t}(z)^{1-\varepsilon} \mathrm{d} z\right)^{\frac{1}{1-\varepsilon}}
$$

Retailers can change their sale price every period with probability $1-\theta$. A fraction $\theta$ stays unchanged every period. The reset price of the retailer is denoted by $P_{t}^{*}(z)$ and $Y_{t+k}^{*}(z)=$ $\left(\frac{P_{t}^{*}(z)}{P_{t+k}}\right)^{-\varepsilon} Y_{t+k}$ is the corresponding demand.

The retailer maximizes the following equation:

$$
\sum_{k=0}^{\infty} \theta^{k} E_{t}\left\{\Lambda_{t, k}\left(\frac{P_{t}^{*}(z)}{P_{t+k}}-\frac{X}{X_{t+k}}\right) Y_{t+k}^{*}(z)\right\}
$$

where $\Lambda_{t, k}=\beta^{k}\left(\frac{c_{t}^{\text {Savers }}}{c_{t+k}^{\text {Savers }}}\right)$ is the patient household relevant discount factor, $X_{t}=\frac{P_{t}}{P_{t}^{w}}$ is the markup of final over intermediate goods and $X$ denotes the steady state value of the markup.

The aggregate price level evolution is given by:

$$
P_{t}=\left(\theta P_{t-1}^{1-\varepsilon}+(1-\theta)\left(P_{t}^{*}\right)^{1-\varepsilon}\right)^{\frac{1}{1-\varepsilon}}
$$

Combining the last two equations and log-linearizing leads to the following formulation of a forward-looking Phillips curve

$$
\hat{\pi}_{t}=\beta E_{t} \pi_{t+1}-\kappa \hat{X}_{t}
$$

where $\kappa \equiv \frac{(1-\theta)(1-\beta \theta)}{\theta}$ and hatted variables denote percent deviations from the steady state. 


\section{E.5. All Benchmark Model Equations}

1. Aggregate demand block

$$
\begin{gathered}
Y_{t}=c_{t}^{\text {Savers }}+c_{t}^{\text {Sub }}+c_{e, t}+c_{b, t}+c_{b b, t} \\
\frac{1}{c_{b, t}}=\beta_{b} E_{t}\left(\frac{R_{b, t}}{c_{b, t+1} \pi_{t+1}}\right)+\left(1-\tau \chi^{\text {intb }}\right) G_{t} \\
\frac{1}{c_{b, t}}=\beta_{b} E_{t}\left(\frac{R_{e, t}}{c_{b, t+1} \pi_{t+1}}\right)+\left(1-\tau \chi^{\text {firm }}\right) G_{t} \\
\frac{1}{c_{b, t}}=\beta_{b} E_{t}\left(\frac{R_{d, t}}{c_{b, t+1} \pi_{t+1}}\right)+G_{t} \\
\frac{1}{c_{t}^{\text {Savers }}}=\beta E_{t}\left(\frac{1}{c_{t+1}^{\text {Savers}} \pi_{t+1}}\right) R_{d, t} \\
\frac{1}{c_{e, t}}=\gamma E_{t}\left(\frac{R_{e, t}}{c_{e, t+1} \pi_{t+1}}\right)+\lambda_{e, t} R_{e, t} \\
\frac{1}{c_{t}^{\text {Sub }}}=\beta^{\text {Sub }} E_{t}\left(\frac{\left(1-\delta_{s, t}\right) R_{s, t}}{c_{t+1}^{\text {Sub }} \pi_{t+1}}\right)+\lambda_{t}^{\text {Sub }} R_{s, t} \\
\frac{R_{s, t}\left(1-\delta_{s, t+1}\right)}{c_{b b, t+1} \pi_{t+1}}+\left(1-\tau^{S u b} \chi^{\text {Sub }}\right)\left(1-\delta_{s}\right) G G_{t} \\
\frac{1}{c_{b b, t}}=\beta_{b} E_{t}\left(\frac{R_{b, t}}{c_{b b, t+1} \pi_{t+1}}\right)+G G_{t}
\end{gathered}
$$

2. Aggregate supply

$$
\begin{gathered}
Y_{t}=h_{e, t-1}^{\nu} L_{t}^{\text {Savers } \alpha(1-\nu)} L_{t}^{\text {Sub }}(1-\alpha)(1-\nu) \\
w_{t}^{\text {Savers }}=\frac{\alpha(1-\mu-\nu) Y_{t}}{X_{t} L_{t}^{\text {Savers }}} \\
w_{t}^{\text {Sub }}=\frac{(1-\alpha)(1-\mu-\nu) s Y_{t}}{X_{t} L_{t}^{\text {Sub }}} \\
\hat{\pi}_{t}=\beta E_{t} \pi_{t+1}-\kappa \hat{X}_{t}
\end{gathered}
$$

3. Housing market block

$$
\begin{gathered}
1=h_{t}^{\text {Savers }}+h_{t}^{\text {Sub }}+h_{e, t} \\
\frac{q_{t}}{c_{t}^{\text {Savers }}}=\beta E_{t}\left(\frac{q_{t+1}}{c_{t+1}^{\text {Savers }}}\right)+\frac{j_{t}}{h_{t}^{\text {Savers }}} \\
\frac{q_{t}}{c_{t}^{\text {Sub }}}=\beta^{\text {Sub }} E_{t}\left(\frac{q_{t+1}}{c_{t+1}^{\text {Sub }}}+\lambda_{t}^{\text {Sub }} m^{\text {Sub }} q_{t+1} \pi_{t+1}\right)+\frac{j_{t}}{h_{t}^{\text {Sub }}}
\end{gathered}
$$




$$
\frac{q_{t}}{c_{e, t}}=E_{t}\left[\frac{\gamma}{c_{e, t+1}}\left(\nu \frac{Y_{t+1}}{X_{t+1} h_{e, t}}+q_{t+1}\right)+\lambda_{e, t} m q_{t+1} \pi_{t+1}\right]
$$

4.Borrowing constraints

$$
\begin{aligned}
R_{s, t} b_{t}^{S u b} & =m^{S u b} E_{t}\left(q_{t+1} \pi_{t+1}\right) h_{t}^{S u b} \\
R_{e, t} b_{e, t} & =m E_{t}\left(q_{t+1} h_{e, t} \pi_{t+1}\right) . \\
\tau= & \frac{b b_{t}+b_{e, t}-d_{t}}{\chi^{I n t b} b b_{t}+\chi^{F i r m} b_{e, t}} \\
\tau^{S u b} & =\frac{\left(1-\delta_{s}\right) b_{t}^{S u b}-b b_{t}}{\chi^{S u b}\left(1-\delta_{s}\right) b_{t}^{S u b}} \\
\delta_{s, t} & =\delta_{s}-\phi_{s, h}\left(q_{t}-Q\right)
\end{aligned}
$$

5. Budget constraints/ evolution of state variables

$$
\begin{gathered}
c_{t}^{\text {Savers }}+q_{t}\left(h_{t}^{\text {Savers }}-h_{t-1}^{\text {Savers }}\right)+d_{t}=R_{d, t-1} d_{t-1} / \pi_{t}+w_{t}^{\text {Savers }} L_{t}^{\text {Savers }}+F_{t} \\
\frac{Y_{t}}{X_{t}}+b_{e, t}=c_{e, t}+q_{t}\left(h_{e, t}-h_{e, t-1}\right)+\frac{R_{e, t-1}}{\pi_{t}} b_{e, t-1}+w_{t}^{\text {Savers }} L_{t}^{\text {Savers }}+w_{t}^{\text {Sub }} L_{t}^{\text {Sub }} \\
c_{b, t}+\frac{R_{d, t-1} d_{t-1}}{\pi_{t}}+b b_{t}+b_{e, t}=d_{t}+\frac{R_{b, t-1} b b_{t-1}}{\pi_{t}}+\frac{R_{e, t-1} b_{e, t-1}}{\pi_{t}} \\
c_{b b, t}+b_{t}^{\text {Sub }}+R_{b, t-1} b b_{t-1} / \pi_{t}=b b_{t}+R_{s, t-1}\left(1-\delta_{s, t}\right) b_{t-1}^{\text {Sub }} / \pi_{t}
\end{gathered}
$$

6. Shock processes and monetary policy rule

$$
\begin{gathered}
\ln j_{t}=\rho_{j} \ln j_{t-1}+\varepsilon_{j, t} \\
R_{d, t}=\left(R_{d, t-1}\right)^{r_{R}} E_{t}\left(\pi_{t-1}^{1+r_{\pi}}\left(\frac{Y_{t-1}}{Y}\right)^{r_{y}} \overline{r r}\right)^{1-r_{R}} e^{\varepsilon_{R, t}} .
\end{gathered}
$$

\section{F. The Option Characteristics of the Tranching Problem}

The payoffs of equity and senior tranche holders resemble payoffs from investment in European options. The holder of an equity tranche of MBS gets payoffs equal to the ones from a long put position - he invests in the hope that the default rate (which can be interpreted as the underlying asset) will decrease. Also, investing in a senior tranche of an MBS is profitable 
when the default rate decreases. Note that

$$
\begin{aligned}
& P_{s}, t=\min \left(S_{t}-f S_{t}, S_{t}-\delta_{s, t} S_{t}\right)=S_{t}(1-f)-\max \left(S_{t} \delta_{s, t}-f S_{t}, 0\right)= \\
& S_{t}\left(1-\delta_{s, t}\right)-\max \left(f S_{t}-\delta_{s, t} S_{t}, 0\right)
\end{aligned}
$$

Thus, the payoff of the senior tranche can be rewritten as having a long position in the face value of the tranche and a short call position, or a long position in the cash flows from subprime loans and a short put. Notice that in the case of the equity tranche and the senior tranche payoff, the face value of the MBS, $S_{t}$, can be factored out. The underlying asset for the investors of MBS tranches is the default of subprime loans $\delta_{s, t}$, whereas the exercise price of the options they trade equals $f$ (the attachment point of senior tranche). Figure 21 visualizes the profit (on the vertical axis) of investing in a short call and long put position depending on the default of subprime loans (horizontal axis). The lower the default, the higher the profit of investors (or the lower the loss).

Senior tranche investor payoff: $S \_t(1-f)+$ short call

Short call: - $\max \left(\delta_{-} s, t S_{-} t-f S_{-} t, 0\right)=\min \left(f S_{-} t-\delta_{-} s, t S_{-} t, 0\right)=S \_t \min \left(f-\delta \_s, t, 0\right)$

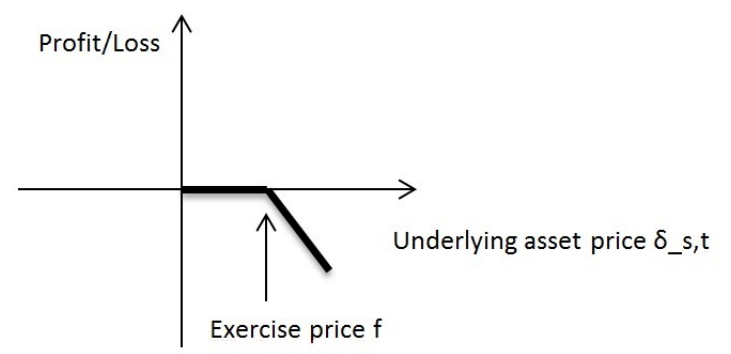

Equity tranche investor payoff: long put

Long put: $\max \left(\mathbf{f S} \_t-\delta \_s, t\right.$ S_t, 0$)=S \_t \max \left(f-\delta \_s, t, 0\right)$

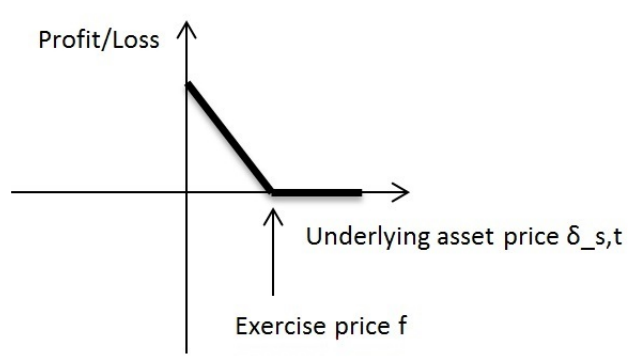

Figure 21: Option position of MBS investors

Independent of the outcome (the size of default), the cash flows distributed from the originator to investors always equal the cash flows from subprime loans (including losses), which is illustrated in Table 3:

\begin{tabular}{|l|l|l|}
\hline & \multicolumn{2}{|c|}{ Scenario } \\
\hline & $\begin{array}{l}\text { Loss }>\text { the equity tranche } \\
\delta_{s, t} S_{t}>f S_{t}\end{array}$ & $\begin{array}{l}\text { Loss < the equity tranche } \\
\delta_{s, t} S_{t}<f S_{t}\end{array}$ \\
\hline Payoff of equity tranche holder & 0 & $f S-\delta_{s, t} S_{t}$ \\
\hline Payoff of senior tranche holder & $S_{t}-\delta_{s, t} S_{t}$ & $S_{t}-f S_{t}$ \\
\hline Sum of payoffs & $S_{t}-\delta_{s, t} S_{t}$ & $S_{t}-\delta_{s, t} S_{t}$ \\
\hline
\end{tabular}

Table 3: MBS payoffs - two scenarios 


\section{Earlier Working Papers:}

For a complete list of Working Papers published by Sveriges Riksbank, see www.riksbank.se

Estimation of an Adaptive Stock Market Model with Heterogeneous Agents

Some Further Evidence on Interest-Rate Smoothing: The Role of Measurement Errors in the Output Gap

by Mikael Apel and Per Jansson

Bayesian Estimation of an Open Economy DSGE Model with Incomplete Pass-Through

by Malin Adolfson, Stefan Laséen, Jesper Lindé and Mattias Villani

Are Constant Interest Rate Forecasts Modest Interventions? Evidence from an Estimated Open Economy

DSGE Model of the Euro Area

by Malin Adolfson, Stefan Laséen, Jesper Lindé and Mattias Villani

Inference in Vector Autoregressive Models with an Informative Prior on the Steady State

by Mattias Villani

Bank Mergers, Competition and Liquidity

2005:182

by Elena Carletti, Philipp Hartmann and Giancarlo Spagnolo

Testing Near-Rationality using Detailed Survey Data

by Michael F. Bryan and Stefan Palmqvist

Exploring Interactions between Real Activity and the Financial Stance

2005:184

by Tor Jacobson, Jesper Lindé and Kasper Roszbach

Two-Sided Network Effects, Bank Interchange Fees, and the Allocation of Fixed Costs

2005:185

by Mats $A$. Bergman

Trade Deficits in the Baltic States: How Long Will the Party Last?

2005:186

by Rudolfs Bems and Kristian Jönsson

Real Exchange Rate and Consumption Fluctuations follwing Trade Liberalization

by Kristian Jönsson

Modern Forecasting Models in Action: Improving Macroeconomic Analyses at Central Banks

by Malin Adolfson, Michael K. Andersson, Jesper Lindé, Mattias Villani and Anders Vredin

Bayesian Inference of General Linear Restrictions on the Cointegration Space

2005:189

by Mattias Villani

Forecasting Performance of an Open Economy Dynamic Stochastic General Equilibrium Model

2005:190

by Malin Adolfson, Stefan Laséen, Jesper Lindé and Mattias Villani

Forecast Combination and Model Averaging using Predictive Measures

2005:191

by Jana Eklund and Sune Karlsson

Swedish Intervention and the Krona Float, 1993-2002

2006:192

by Owen F. Humpage and Javiera Ragnartz

A Simultaneous Model of the Swedish Krona, the US Dollar and the Euro

2006:193

by Hans Lindblad and Peter Sellin

Testing Theories of Job Creation: Does Supply Create Its Own Demand?

2006:194

by Mikael Carlsson, Stefan Eriksson and Nils Gottfries

Down or Out: Assessing The Welfare Costs of Household Investment Mistakes

2006:195

by Laurent E. Calvet, John Y. Campbell and Paolo Sodini

Efficient Bayesian Inference for Multiple Change-Point and Mixture Innovation Models

2006:196

by Paolo Giordani and Robert Kohn

Derivation and Estimation of a New Keynesian Phillips Curve in a Small Open Economy

2006:197

by Karolina Holmberg

Technology Shocks and the Labour-Input Response: Evidence from Firm-Level Data

2006:198

by Mikael Carlsson and Jon Smedsaas

Monetary Policy and Staggered Wage Bargaining when Prices are Sticky

2006:199

by Mikael Carlsson and Andreas Westermark

The Swedish External Position and the Krona

by Philip R. Lane 
Using a New Open Economy Macroeconomics model to make real nominal exchange rate forecasts 
Evaluating Microfoundations for Aggregate Price Rigidities: Evidence from Matched Firm-Level Data on

Flexible Modeling of Conditional Distributions Using Smooth Mixtures of Asymmetric

Student T Densities

by Feng Li, Mattias Villani and Robert Kohn

Forecasting Macroeconomic Time Series with Locally Adaptive Signal Extraction

Risk Premiums and Macroeconomic Dynamics in a Heterogeneous Agent Model by Ferre De Graeve, Maarten Dossche, Marina Emiris, Henri Sneessens and Raf Wouters

Picking the Brains of MPC Members

by Mikael Apel, Carl Andreas Claussen and Petra Lennartsdotter

Involuntary Unemployment and the Business Cycle

by Lawrence J. Christiano, Mathias Trabandt and Karl Walentin

Housing collateral and the monetary transmission mechanism

by Karl Walentin and Peter Sellin

The Discursive Dilemma in Monetary Policy

by Carl Andreas Claussen and Øistein Røisland

Monetary Regime Change and Business Cycles

Bayesian Inference in Structural Second-Price common Value Auctions

by Bertil Wegmann and Mattias Villani

Equilibrium asset prices and the wealth distribution with inattentive consumers

by Luca Sala, Ulf Söderström and Antonella Trigari

Density-Conditional Forecasts in Dynamic Multivariate Models

by Michael K. Andersson, Stefan Palmqvist and Daniel F. Waggoner

Anticipated Alternative Policy-Rate Paths in Policy Simulations

by Stefan Laséen and Lars E. O. Svensson

MOSES: Model of Swedish Economic Studies

by Gunnar Bårdsen, Ard den Reijer, Patrik Jonasson and Ragnar Nymoen

The Effects of Endogenuos Firm Exit on Business Cycle Dynamics and Optimal Fiscal Policy

by Lauri Vilmi

Parameter Identification in a Estimated New Keynesian Open Economy Model 
The Cost of Consumer Payments in Sweden

by Björn Segendorf and Thomas Jansson

Trade Credit and the Propagation of Corporate Failure: An Empirical Analysis

by Tor Jacobson and Erik von Schedvin

Structural and Cyclical Forces in the Labor Market During the Great Recession: Cross-Country Evidence

by Luca Sala, Ulf Söderström and AntonellaTrigari

Pension Wealth and Household Savings in Europe: Evidence from SHARELIFE

by Rob Alessie, Viola Angelini and Peter van Santen

Long-Term Relationship Bargaining

by Andreas Westermark

Using Financial Markets To Estimate the Macro Effects of Monetary Policy: An Impact-Identified FAVAR*

by Stefan Pitschner

DYNAMIC MIXTURE-OF-EXPERTS MODELS FOR LONGITUDINAL AND DISCRETE-TIME SURVIVAL DATA

by Matias Quiroz and Mattias Villani

Conditional euro area sovereign default risk

by André Lucas, Bernd Schwaab and Xin Zhang

Nominal GDP Targeting and the Zero Lower Bound: Should We Abandon Inflation Targeting?*

by Roberto M. Billi

Un-truncating VARs*

by Ferre De Graeve and Andreas Westermark

Housing Choices and Labor Income Risk

by Thomas Jansson

Identifying Fiscal Inflation*

by Ferre De Graeve and Virginia Queijo von Heideken

On the Redistributive Effects of Inflation: an International Perspective*

by Paola Boel

Business Cycle Implications of Mortgage Spreads*

by Karl Walentin

Approximate dynamic programming with post-decision states as a solution method for dynamic

by Christoph Bertsch

Distortionary Fiscal Policy and Monetary Policy Goals 
by Karolina Holmberg

A wake-up call: information contagion and strategic uncertainty

by Toni Ahnert and Christoph Bertsch

Debt Dynamics and Monetary Policy: A Note

by Stefan Laséen and Ingvar Strid

Optimal taxation with home production

by Conny Olovsson

Incompatible European Partners? Cultural Predispositions and Household Financial Behavior

by Michael Haliassos, Thomas Jansson and Yigitcan Karabulut

How Subprime Borrowers and Mortgage Brokers Shared the Piecial Behavior

by Antje Berndt, Burton Hollifield and Patrik Sandàs

The Macro-Financial Implications of House Price-Indexed Mortgage Contracts

by Isaiah Hull

Does Trading Anonymously Enhance Liquidity?

by Patrick J. Dennis and Patrik Sandås

Systematic bailout guarantees and tacit coordination

by Christoph Bertsch, Claudio Calcagno and Mark Le Quement

Selection Effects in Producer-Price Setting

by Mikael Carlsson

Dynamic Demand Adjustment and Exchange Rate Volatility

by Vesna Corbo

Forward Guidance and Long Term Interest Rates: Inspecting the Mechanism

by Ferre De Graeve, Pelin Ilbas \& Raf Wouters

Firm-Level Shocks and Labor Adjustments

by Mikael Carlsson, Julián Messina and Oskar Nordström Skans

A wake-up call theory of contagion

by Toni Ahnert and Christoph Bertsch

Risks in macroeconomic fundamentals and excess bond returns predictability

by Rafael B. De Rezende

The Importance of Reallocation for Productivity Growth: Evidence from European and US Banking

by Matias Quiroz, Mattias Villani and Robert Kohn

Amortization Requirements and Household Indebtedness: An Application to Swedish-Style Mortgages

by Isaiah Hull

Fuel for Economic Growth?

by Johan Gars and Conny Olovsson

Searching for Information

by Jungsuk Han and Francesco Sangiorgi

What Broke First? Characterizing Sources of Structural Change Prior to the Great Recession

Price Level Targeting and Risk Management

by Roberto Billi

Central bank policy paths and market forward rates: A simple model

by Ferre De Graeve and Jens Iversen

Jump-Starting the Euro Area Recovery: Would a Rise in Core Fiscal Spending Help the Periphery? 
Optimal Inflation with Corporate Taxation and Financial Constraints

by Daria Finocchiaro, Giovanni Lombardo, Caterina Mendicino and Philippe Weil

Fire Sale Bank Recapitalizations

by Christoph Bertsch and Mike Mariathasan

Since you're so rich, you must be really smart: Talent and the Finance Wage Premium 